Portland State University

PDXScholar

10-20-1998

\title{
Measurements of Methane Emissions from Rice Fields in China
}

\author{
M. A. K. Khalil \\ Portland State University, aslamk@pdx.edu \\ R. A. Rasmussen \\ Oregon Graduate Institute \\ Martha J. Shearer \\ Portland State University \\ R. W. Dalluge \\ Oregon Graduate Institute \\ Lixin Ren \\ Academia Sinic
}

See next page for additional authors

Follow this and additional works at: https://pdxscholar.library.pdx.edu/phy_fac

Part of the Physics Commons

Let us know how access to this document benefits you.

\section{Citation Details}

Khalil, M. A. K., R. A. Rasmussen, M. J. Shearer, R. W. Dalluge, L. X. Ren, and C.-L. Duan (1998),

Measurements of methane emissions from rice fields in China, J. Geophys. Res., 103(D19),

25,181-25,210, doi:10.1029/97JD02611.

This Article is brought to you for free and open access. It has been accepted for inclusion in Physics Faculty Publications and Presentations by an authorized administrator of PDXScholar. Please contact us if we can make this document more accessible: pdxscholar@pdx.edu. 
Authors

M. A. K. Khalil, R. A. Rasmussen, Martha J. Shearer, R. W. Dalluge, Lixin Ren, and Chang-Lin Duan 


\title{
Measurements of methane emissions from rice fields in China
}

\author{
M. A. K. Khalil, ${ }^{1}$ R. A. Rasmussen, ${ }^{2}$ M. J. Shearer, ${ }^{1}$ R. W. Dalluge, ${ }^{2}$ \\ L. X. Ren, ${ }^{3}$ and C.- L. Duan ${ }^{4}$
}

\begin{abstract}
Rice fields have always been regarded as one of the largest anthropogenic sources of atmospheric methane. Here we report the results of a 7-year study of methane emissions from rice fields in the Sichuan Province of China. In this region, there is one crop of rice per year, the fields are continuously flooded from transplanting to harvest, and there is heavy use of organic fertilizers. Emissions over the entire growing season were measured from each of up to 24 plots. Environmental variables were measured and relevant supporting data on the agricultural practices were recorded. The fields were studied under prevailing agricultural practices of the local farmers. The results represent emissions under standard agricultural practices and the year to year variability of climate, fertilizers, available irrigation water, and cultivars. Based on some 5000 flux measurements, the average emission rates between 1988 and 1994 were $30 \mathrm{mg} / \mathrm{m}^{2} / \mathrm{h}$ for a growing season of between 100 and 120 days. This emission rate is comparable to other published data from similar rice fields but somewhat on the high side of the range. There were no systematic trends of emissions during the 7 years of our experiment, but there was substantial year to year variability. The data have been subjected to exhaustive analyses for validity, accuracy, and reliability. From this, a high-quality, spatially averaged data set has been constructed representing average emissions from the rice fields for each day when measurements were taken. We describe here the main observational results and document the spatial and temporal variability observed on timescales ranging from a day to several years and on spatial scales ranging from 0.5 $\mathrm{m}^{2}$ to $16 \mathrm{~m}^{2}$.
\end{abstract}

\section{Introduction}

Methane is a potent greenhouse gas in Earth's environment. Some years ago we showed that its atmospheric concentrations were rapidly increasing [Rasmussen and Khalil, 1981]. Even the earliest studies suggested that the increase of methane over the last century and in recent times may be caused in part by the increase of rice agriculture. The hectares of rice harvested have doubled during the last century, and the rice fields are a substantial source in every budget of methane [Khalil and Rasmussen, 1990].

In the mid-1980s, we proposed to systematically study the emission of methane from rice fields. Work started on this project in 1985 [Riches et al., 1992]. The first systematic measurements were taken in 1988 . This was a relatively early effort to measure the emissions of methane from rice fields and the factors that control the emission rates [Khalil et al., 1990]. As the experiment unfolded, the complexities of the processes in the rice fields became apparent, requiring new experiments to validate and interpret the early data. This work has been completed, and we are reporting the results here.

\footnotetext{
'Department of Physics, Portland State University, Portland, Oregon 2 Department of Environmental Science and Engineering, Oregon Graduate Institute, Portland, Oregon

${ }^{3}$ Institute of Atmospheric Physics, Academia Sinica, Beijing, China

${ }^{4}$ Institute of Mountain Disasters and the Environment, Chengdu, Sichuan, China.
}

Copyright 1998 by the American Geophysical Union.

Paper number 97JD02611.

0148-0227/98/97JD-02611\$09.00
This study is unique for several reasons: it spans seven years of measurements, which is the longest record available at any one location and shows the inter-annual variability of methane emıssions; it includes many replicates, up to 24 plots in some years, that show the spatial variability of methane emissions and puts constraints on how well we can extrapolate field data to the global scale; it covers the entire growing season each year; it includes simultaneous measurements of environmental and agricultural parameters that affect methane emissions; it was done under the prevailing agricultural practices of the region; and it was conducted in China, which is the largest rice-producing country in the world.

This paper is the foundation for the results that we have obtained. We have included what we consider to be the most useful form of the data in Tables 1 and 2 so that readers may use it for their own purposes. More detailed versions of the data, discussed here, may be obtained from the archives at the Carbon Dioxide Information and Assessment Center (Oak Ridge National Laboratory, Oak Ridge, Tennessee). The main purpose of this paper is to describe the data set and the conditions under which it was acquired, to describe its salient features, to establish its quality and reliability, and to delineate the uncertainties and the inherent variability that were observed. Furthermore, this paper documents the seasonal and annual emission rates of methane from up to 24 plots in four fields that were studied over the 7year period from 1988 to 1994.

\section{Experimental Design and Methods}

\subsection{Location and Site Description}

The site was located in the village of $\mathrm{Tu} \mathrm{Zu}$, about $20 \mathrm{~km}$ east of Leshan City and $100 \mathrm{~km}$ south of Chengdu, in the Sichuan 
Table 1. Measured Flux of Methane

\begin{tabular}{|c|c|c|c|c|c|c|c|c|c|c|c|}
\hline Date & Time & $\begin{array}{l}\text { Days } \\
\text { After } \\
\text { Trans- } \\
\text { plant }\end{array}$ & Flux & SE & $\begin{array}{l}T \text {-soil, } \\
{ }^{\circ} \mathrm{C}\end{array}$ & Date & Time & $\begin{array}{l}\text { Days } \\
\text { After } \\
\text { Trans- } \\
\text { plant }\end{array}$ & Flux & SE & $\begin{array}{l}T \text {-soil, } \\
{ }^{\circ} \mathrm{C}\end{array}$ \\
\hline Apr 22, 1988 & 1150 & 1 & 2.3 & 0.7 & & Jun 23, 1988 & 0750 & 63 & 39.4 & 2.3 & 26.4 \\
\hline Apr 23,1988 & 1330 & 2 & 1.5 & 0.4 & & Jun 24,1988 & 1925 & 64 & 47.2 & 4.1 & 29.2 \\
\hline Apr 24,1988 & 0735 & 3 & 4.9 & 2.9 & & Jun 27,1988 & 0802 & 67 & 37.6 & 2.1 & 25.0 \\
\hline Apr 25, 1988 & 0902 & 4 & 1.8 & 0.4 & & Jun 28,1988 & 1913 & 68 & 48.5 & 4.5 & 28.2 \\
\hline Apr 26,1988 & 2002 & 5 & 2.0 & 0.3 & & Jun 30,1988 & 0758 & 70 & 42.8 & 2.1 & 27.2 \\
\hline Apr 28,1988 & 0908 & 7 & 2.1 & 0.2 & 16.3 & Jul 0I, 1988 & 1907 & 71 & 42.9 & 2.3 & 26.8 \\
\hline Apr 29,1988 & 2023 & 8 & 4.1 & 0.8 & 24.8 & Jul 04, 1988 & 0803 & 74 & 30.0 & 1.6 & 23.4 \\
\hline May 02, 1988 & 0827 & 11 & 10.6 & 0.9 & 21.8 & Jul 05, 1988 & 1901 & 75 & 34.9 & 2.6 & 25.1 \\
\hline May 03, 1988 & 1937 & 12 & 19.4 & 3.6 & 30.0 & Jul 07, 1988 & 0755 & 77 & 36.4 & 2.4 & 25.2 \\
\hline May 05, 1988 & 0834 & 14 & 14.1 & 1.1 & 23.5 & Jul 08, 1988 & 1912 & 78 & 40.6 & 3.1 & 25.5 \\
\hline May 06, 1988 & 2007 & 15 & 25.1 & 4.6 & 28.4 & Jul 11, 1988 & 0751 & 81 & 32.8 & 1.9 & 24.5 \\
\hline May 09, 1988 & 0835 & 18 & 12.7 & 1.4 & 20.2 & Jul 12,1988 & 1913 & 82 & 47.6 & 3.2 & 28.3 \\
\hline May 10,1988 & 1923 & 19 & 14.0 & 1.5 & 20.1 & Jul 14,1988 & 0757 & 84 & 40.7 & 2.3 & 26.8 \\
\hline May 12,1988 & 0827 & 21 & 13.2 & 1.0 & 17.9 & Jul 15,1988 & 1909 & 85 & 49.0 & 5.0 & 28.3 \\
\hline May 13,1988 & 1919 & 22 & 10.8 & 0.9 & 19.9 & Jul 18, 1988 & 0753 & 88 & 47.7 & 5.0 & 26.6 \\
\hline May 16,1988 & 0832 & 25 & 19.7 & 1.8 & 21.4 & Jul 19, 1988 & 1912 & 89 & 60.7 & 5.4 & 28.2 \\
\hline May 20,1988 & 1942 & 29 & 30.8 & 4.5 & 26.4 & Jul 21,1988 & 0757 & 91 & 48.3 & 4.3 & 26.4 \\
\hline May 23,1988 & 0828 & 32 & 32.1 & 2.2 & 22.9 & Jul 22, 1988 & 1915 & 92 & 61.3 & 6.6 & 29.4 \\
\hline May 24,1988 & 1917 & 33 & 30.5 & 2.2 & 24.3 & Jul 25, 1988 & 0807 & 95 & 46.9 & 4.6 & 25.6 \\
\hline May 26,1988 & 0825 & 35 & 28.5 & 1.8 & 20.9 & Jul 26, 1988 & 1910 & 96 & 48.4 & 5.4 & 27.2 \\
\hline May 27,1988 & 1908 & 36 & 27.4 & 2.2 & 21.1 & Jul 28, 1988 & 0808 & 98 & 53.3 & 8.6 & 26.4 \\
\hline May 30,1988 & 0851 & 39 & 31.2 & 2.0 & 20.7 & Jul 29, 1988 & 1926 & 99 & 57.7 & 8.5 & 27.0 \\
\hline May 31,1988 & 1939 & 40 & 34.6 & 1.9 & 27.3 & Aug 01,1988 & 0755 & 102 & 27.0 & 2.0 & 24.7 \\
\hline Jun 02,1988 & 0809 & 42 & 37.6 & 2.5 & 22.2 & Aug 02, 1988 & 1915 & 103 & 37.6 & 5.3 & 26.9 \\
\hline Jun 03,1988 & 1930 & 43 & 48.2 & 3.6 & 29.5 & Aug 04, 1988 & 0816 & 105 & 30.7 & 2.2 & 25.9 \\
\hline Jun 06, 1988 & 0815 & 46 & 42.0 & 3.0 & 23.2 & Aug 05, 1988 & 1917 & 106 & 50.7 & 6.0 & 26.6 \\
\hline Jun 07,1988 & 1906 & 47 & 45.5 & 3.0 & 27.6 & Aug 08, 1988 & 0810 & 109 & 34.0 & 6.4 & 26.0 \\
\hline Jun 09,1988 & 0807 & 49 & 42.7 & 2.7 & 24.7 & Aug 09, 1988 & 1917 & 110 & 48.1 & 6.1 & 26.7 \\
\hline Jun 10,1988 & 1905 & 50 & 36.1 & 2.2 & 24.5 & Aug 11, 1988 & 0936 & 112 & 18.5 & 3.8 & 25.6 \\
\hline Jun 13,1988 & 0755 & 53 & 32.8 & 1.9 & 24.0 & Aug 12, 1988 & 1916 & 113 & 27.8 & 3.7 & 26.0 \\
\hline Jun 14,1988 & 1913 & 54 & 36.5 & 2.2 & 27.6 & Aug 15,1988 & 0811 & 116 & 22.7 & 4.6 & 23.8 \\
\hline Jun 16,1988 & 0834 & 56 & 34.1 & 2.0 & 23.6 & Aug 16,1988 & 1914 & 117 & 42.1 & 5.6 & 25.8 \\
\hline Jun 17,1988 & 1929 & 57 & 32.2 & 1.5 & 23.7 & Aug 18, 1988 & 0811 & 119 & 12.3 & 1.5 & 25.1 \\
\hline Jun 20,1988 & 0804 & 60 & 35.2 & 1.6 & 24.7 & Aug 19,1988 & 1918 & 120 & 36.2 & 6.6 & 26.7 \\
\hline Jun 21, 1988 & 1916 & 61 & 40.4 & 2.6 & 27.6 & & & & & & \\
\hline May 01, 1989 & 0855 & 11 & 6.2 & 0.7 & 18.4 & Jun 30, 1989 & 1831 & 71 & 15.4 & 1.3 & 25.7 \\
\hline May 02, 1989 & 1850 & 12 & 5.7 & 1.5 & 25.6 & Jul 03, 1989 & 0909 & 74 & 17.5 & 1.4 & 23.3 \\
\hline May 04, 1989 & 0920 & 14 & 7.1 & 1.3 & 21.2 & Jul 04, 1989 & 1842 & 75 & 20.4 & 1.8 & 24.7 \\
\hline May 05, 1989 & 1858 & 15 & 11.1 & 2.5 & 25.2 & Jul 06, 1989 & 0907 & 77 & 24.8 & 3.1 & 24.9 \\
\hline May 08, 1989 & 0913 & 18 & 9.6 & 1.2 & 21.0 & Jul 07, 1989 & 1839 & 78 & 25.7 & 3.8 & 27.3 \\
\hline May 09, 1989 & 1844 & 19 & 15.6 & 5.0 & 22.8 & Jul 10, 1989 & 0913 & 81 & 23.8 & 3.4 & 24.7 \\
\hline May 11,1989 & 0910 & 21 & 11.0 & 1.3 & 20.0 & Jul 11,1989 & 1842 & 82 & 22.5 & 1.7 & 30.3 \\
\hline May 12,1989 & 1856 & 22 & 18.2 & 3.5 & 19.8 & Jul 13,1989 & 0907 & 84 & 28.7 & 2.2 & 24.8 \\
\hline May 15,1989 & 0911 & 25 & 9.3 & 1.0 & 18.7 & Jul 14,1989 & 1837 & 85 & 35.9 & 4.9 & 28.7 \\
\hline May 16,1989 & 1837 & 26 & 21.0 & 5.2 & 28.2 & Jul 17,1989 & 0907 & 88 & 38.6 & 3.6 & 24.6 \\
\hline May 18, 1989 & 0913 & 28 & 14.0 & 1.9 & 20.9 & Jul 18, 1989 & 1849 & 89 & 46.8 & 5.1 & 30.2 \\
\hline May 19, 1989 & 1837 & 29 & 15.9 & 1.8 & 29.5 & Jul 20,1989 & 0907 & 91 & 37.9 & 5.3 & 27.0 \\
\hline May 22,1989 & 0914 & 32 & 13.0 & 1.1 & 19.8 & Jul 21, 1989 & 1842 & 92 & 51.5 & 7.0 & 32.5 \\
\hline May 23,1989 & 1842 & 33 & 19.8 & 4.1 & 28.7 & Jul 24, 1989 & 0905 & 95 & 41.2 & 6.0 & 26.6 \\
\hline May 25, 1989 & 0909 & 35 & 21.5 & 1.9 & 22.0 & Jul 25, 1989 & 1843 & 96 & 30.4 & 2.9 & 25.5 \\
\hline May 26, 1989 & 1838 & 36 & 19.8 & 2.8 & 25.5 & Jul 27, 1989 & 0905 & 98 & 41.6 & 5.1 & 23.9 \\
\hline May 29,1989 & 0905 & 39 & 22.4 & 1.7 & 22.9 & Jul 28,1989 & 1840 & 99 & 40.9 & 4.6 & 27.1 \\
\hline May 30,1989 & 1834 & 40 & 19.3 & 1.8 & 22.8 & Jul 31, 1989 & 0900 & 102 & 30.7 & 4.4 & 25.1 \\
\hline Jun 01, 1989 & 0857 & 42 & 21.1 & 1.6 & 23.0 & Aug 01, 1989 & 1842 & 103 & 35.9 & 4.1 & 28.0 \\
\hline Jun 02, 1989 & 1837 & 43 & 27.2 & 2.5 & 27.8 & Aug 03, 1989 & 0905 & 105 & 31.0 & 4.2 & 26.2 \\
\hline
\end{tabular}


Table 1 continued

\begin{tabular}{|c|c|c|c|c|c|c|c|c|c|c|c|}
\hline Date & Time & $\begin{array}{l}\text { Days } \\
\text { After } \\
\text { Trans- } \\
\text { plant }\end{array}$ & Flux & SE & $\begin{array}{l}T \text {-soil, } \\
{ }^{\circ} \mathrm{C}\end{array}$ & Date & Time & $\begin{array}{l}\text { Days } \\
\text { After } \\
\text { Trans- } \\
\text { plant }\end{array}$ & Flux & SE & $\begin{array}{l}T \text {-soil, } \\
{ }^{\circ} \mathrm{C}\end{array}$ \\
\hline Jun 05, 1989 & 0908 & 46 & 29.8 & 2.0 & 24.3 & Aug 04, 1989 & 1845 & 106 & 32.8 & 4.6 & 27.5 \\
\hline Jun 06, 1989 & 1836 & 47 & 37.2 & 5.3 & 25.9 & Aug 07, 1989 & 0906 & 109 & 30.2 & 5.5 & 25.0 \\
\hline Jun 08, 1989 & 0903 & 49 & 21.1 & 2.2 & 23.0 & Aug 08, 1989 & 1834 & 110 & 31.4 & 6.4 & 29.9 \\
\hline Jun 09, 1989 & 1839 & 50 & 21.1 & 2.7 & 25.8 & Aug 10, 1989 & 0911 & 112 & 25.4 & 3.5 & 25.2 \\
\hline Jun 12,1989 & 0907 & 53 & 17.0 & 2.9 & 24.9 & Aug 11, 1989 & 1831 & 113 & 28.3 & 5.8 & 28.8 \\
\hline Jun 13, 1989 & 1805 & 54 & 16.3 & 2.6 & 25.7 & Aug 14, 1989 & 0922 & 116 & 20.9 & 1.7 & 25.2 \\
\hline Jun 15,1989 & 0909 & 56 & 15.7 & 1.9 & 23.7 & Aug 15, 1989 & 1848 & 117 & 21.0 & 2.8 & 29.1 \\
\hline Jun 16,1989 & 1840 & 57 & 17.0 & 2.4 & 24.4 & Aug 17, 1989 & 0925 & 119 & 32.6 & 5.1 & 24.8 \\
\hline Jun 19,1989 & 0907 & 60 & 14.5 & 1.3 & 20.9 & Aug 18, 1989 & 1833 & 120 & 22.7 & 2.9 & 26.4 \\
\hline Jun 20, 1989 & 1836 & 61 & 14.6 & 1.4 & 22.9 & Aug 21, 1989 & 0907 & 123 & 22.1 & 3.8 & 23.5 \\
\hline Jun 22, 1989 & 0907 & 63 & 15.2 & 1.2 & 22.4 & Aug 22, 1989 & 1855 & 124 & 30.6 & 7.6 & 29.0 \\
\hline Jun 23, 1989 & 1839 & 64 & 15.1 & 1.2 & 22.9 & Aug 24, 1989 & 0910 & 126 & 19.0 & 2.6 & 24.9 \\
\hline Jun 26,1989 & 0906 & 67 & 17.4 & 1.6 & 23.5 & Aug 25, 1989 & 1836 & & & & 24.3 \\
\hline Jun 27, 1989 & 1836 & 68 & 12.9 & 1.7 & 25.1 & & & & & & \\
\hline Jun 29, 1989 & 0909 & 70 & 15.0 & 1.1 & 23.8 & & & & & & \\
\hline May 07, 1990 & 0907 & 8 & 6.0 & 0.5 & 20.3 & Jul 13, 1990 & 1909 & 75 & 53.4 & 6.3 & 24.5 \\
\hline May 08, 1990 & 1908 & 9 & 12.4 & 1.5 & 28.1 & Jul 16, 1990 & 0907 & 78 & 56.2 & 5.9 & 24.7 \\
\hline May 10,1990 & 0853 & 11 & 9.1 & 0.5 & 19.5 & Jul 17, 1990 & 1904 & 79 & 54.0 & 4.8 & 22.5 \\
\hline May 11,1990 & 1904 & 12 & 17.6 & 1.9 & 28.0 & Jul 19, 1990 & 0904 & 81 & 47.7 & 3.5 & 22.4 \\
\hline May 14, 1990 & 0907 & 15 & 21.5 & 2.2 & 22.4 & Jul 20, 1990 & 1905 & 82 & 46.1 & 3.3 & 22.9 \\
\hline May 15,1990 & 1907 & 16 & 15.5 & 1.3 & 22.9 & Jul 23, 1990 & 0914 & 85 & 50.5 & 4.6 & 22.9 \\
\hline May 17,1990 & 0901 & 18 & 17.3 & 1.1 & 19.5 & Jul 24, 1990 & 1918 & 86 & 54.6 & 4.7 & 27.3 \\
\hline May 18, 1990 & 1905 & 19 & 21.7 & 3.0 & 28.2 & Jul 26, 1990 & 0913 & 88 & 41.3 & 4.1 & 22.9 \\
\hline May 21,1990 & 0859 & 22 & 18.8 & 1.6 & 18.3 & Jul 27, 1990 & 1907 & 89 & 48.8 & 6.3 & 27.5 \\
\hline May 22, 1990 & 1906 & 23 & 20.2 & 1.6 & 19.2 & Jul 30, 1990 & 0906 & 92 & 30.2 & 3.5 & 24.4 \\
\hline Jun 24, 1990 & 0906 & 25 & 20.5 & 1.8 & 17.7 & Jul 31, 1990 & 1845 & 93 & 37.9 & 4.7 & 27.3 \\
\hline Jun 25,1990 & 1907 & 26 & 31.4 & 2.3 & 26.1 & Aug 02, 1990 & 0907 & 95 & 28.3 & 2.5 & 26.4 \\
\hline Jun 28,1990 & 0908 & 29 & 43.2 & 2.8 & 20.5 & Aug 03, 1990 & 1906 & 96 & 30.2 & 3.2 & 27.3 \\
\hline Jul 02, 1990 & 0912 & 64 & 56.0 & 11.4 & 23.3 & Aug 06, 1990 & 0905 & 99 & 25.1 & 2.6 & 24.0 \\
\hline Jul 03, 1990 & 1911 & 65 & 79.7 & 5.6 & 28.2 & Aug 07, 1990 & 1906 & 100 & 25.5 & 3.4 & 29.5 \\
\hline Jul 05, 1990 & 0911 & 67 & 66.5 & 6.9 & 24.9 & Aug 09, 1990 & 0907 & 102 & 24.9 & 2.3 & 24.0 \\
\hline Jul 06, 1990 & 1907 & 68 & 74.9 & 5.3 & 25.9 & Aug 10, 1990 & 1906 & 103 & 32.6 & 5.1 & 29.8 \\
\hline Jul 09, 1990 & 0909 & 71 & 59.4 & 4.5 & 25.0 & Aug 13, 1990 & 0923 & 106 & 21.1 & 3.0 & 23.9 \\
\hline Jul 10, 1990 & 1914 & 72 & 81.3 & 5.4 & 27.9 & Aug 14, 1990 & 1910 & 107 & 22.2 & 2.7 & 27.2 \\
\hline \multirow[t]{3}{*}{ Jul 12, 1990} & 0914 & 74 & 70.8 & 4.9 & 22.5 & Aug 16, 1990 & 0920 & 109 & 21.1 & 2.7 & 23.6 \\
\hline & & & & & & Aug 17, 1990 & 1906 & 110 & 30.2 & 5.3 & 27.0 \\
\hline & & & & & & Aug 20, 1990 & 0908 & 113 & 18.7 & 3.1 & 23.4 \\
\hline May 27,1991 & 0825 & 34 & 12.7 & 4.6 & 26.2 & Jul 04, 1991 & 0825 & 72 & 37.5 & 4.0 & 23.3 \\
\hline May 28, 1991 & 1825 & 35 & 10.0 & 1.2 & 24.2 & Jul 05, 1991 & 1825 & 73 & 34.2 & 5.6 & 27.2 \\
\hline May 30,1991 & 0825 & 37 & 21.8 & 2.2 & 21.9 & Jul 08, 1991 & 0825 & 76 & 46.8 & 11.8 & 21.9 \\
\hline May 31,1991 & 1825 & 38 & 31.2 & 2.1 & 26.7 & Jul 09, 1991 & 1825 & 77 & 40.0 & 9.2 & 27.3 \\
\hline Jun 03, 1991 & 0824 & 41 & 37.5 & 6.8 & 21.1 & Jul 11, 1991 & 0825 & 79 & 30.4 & 6.6 & 23.3 \\
\hline Jun 04, 1991 & 1825 & 42 & 29.0 & 2.8 & 25.2 & Jul 12, 1991 & 1831 & 80 & 30.8 & 10.1 & 26.8 \\
\hline Jun 06, 1991 & 0825 & 44 & 32.1 & 1.9 & 22.8 & Jul 15, 1991 & 0825 & 83 & 25.4 & 8.0 & 24.2 \\
\hline Jun 07, 1991 & 1825 & 45 & 36.6 & 3.1 & 26.4 & Jul 16, 1991 & 1825 & 84 & 22.7 & 5.6 & 27.3 \\
\hline Jun 10,1991 & 0825 & 48 & 46.7 & 3.5 & 23.5 & Jul 18, 1991 & 0825 & 86 & 22.3 & 3.7 & 24.8 \\
\hline Jun 11,1991 & 1825 & 49 & 35.7 & 5.4 & 30.6 & Jul 19, 1991 & 1825 & 87 & 24.6 & 2.7 & 28.9 \\
\hline Jun 13,1991 & 0825 & 51 & 38.3 & 5.6 & 24.8 & Jul 22, 1991 & 0825 & 90 & 33.6 & 9.0 & 24.5 \\
\hline Jun 14, 1991 & 1825 & 52 & 46.0 & 2.1 & 24.5 & Jul 23, 1991 & 1825 & 91 & 25.0 & 6.6 & 28.2 \\
\hline Jun 17,1991 & 0825 & 55 & 41.3 & 1.6 & 24.5 & Jul 25, 1991 & 0816 & 93 & 31.1 & 10.7 & 26.1 \\
\hline Jun 18,1991 & 1825 & 56 & 41.7 & 5.4 & 23.5 & Jul 26, 1991 & 1825 & 94 & 26.8 & 7.1 & 27.6 \\
\hline Jun 20,1991 & 0825 & 58 & 44.9 & 6.2 & 23.0 & Jul 29, 1991 & 0825 & 97 & 27.8 & 5.2 & 27.7 \\
\hline Jun 21,1991 & 1825 & 59 & 51.1 & 3.3 & 24.0 & Jul 30, 1991 & 1825 & 98 & 19.9 & 4.2 & 23.8 \\
\hline Jun 24,1991 & 0825 & 62 & 46.5 & 8.3 & 23.5 & Aug 01, 1991 & 1825 & 100 & 41.6 & 11.9 & 21.9 \\
\hline Jun 28,1991 & 1825 & 66 & 39.5 & 2.2 & 26.4 & Aug 02, 1991 & 1825 & 101 & 18.3 & 5.8 & 24.0 \\
\hline
\end{tabular}


Table 1 continued

\begin{tabular}{|c|c|c|c|c|c|c|c|c|c|c|c|}
\hline Date & Time & $\begin{array}{l}\text { Days } \\
\text { After } \\
\text { Trans- } \\
\text { plant }\end{array}$ & Flux & SE & $\begin{array}{l}T \text {-soil, } \\
{ }^{\circ} \mathrm{C}\end{array}$ & Date & Time & $\begin{array}{l}\text { Days } \\
\text { After } \\
\text { Trans- } \\
\text { plant }\end{array}$ & Flux & SE & $\begin{array}{l}T \text {-soil, } \\
{ }^{\circ} \mathrm{C}\end{array}$ \\
\hline Jul 01, 1991 & 0825 & 69 & 41.3 & 5.8 & 21.5 & Aug 05, 1991 & 0825 & 104 & 29.3 & 15.7 & 23.3 \\
\hline \multirow[t]{4}{*}{ Jul 02, 1991} & 1826 & 70 & 39.4 & 5.8 & 26.2 & Aug 06, 1991 & 1825 & 105 & 25.5 & 8.8 & 27.5 \\
\hline & & & & & & Aug 08, 1991 & 1825 & 107 & 33.4 & 10.9 & 24.9 \\
\hline & & & & & & Aug 09, 1991 & 1825 & 108 & 17.4 & 3.2 & 23.8 \\
\hline & & & & & & Aug 12, 1991 & 0829 & 111 & 31.4 & 12.7 & 23.1 \\
\hline May 18, 1992 & 1753 & 15 & 22.0 & 4.6 & 18.6 & Jun 30, 1992 & 0752 & 58 & 22.2 & 3.5 & 21.8 \\
\hline May 19, 1992 & 0843 & 16 & 20.5 & 5.2 & 17.3 & Jul 02, 1992 & 1800 & 60 & 32.8 & 5.0 & 24.2 \\
\hline May 21, 1992 & 1807 & 18 & 22.3 & 4.0 & 27.3 & Jul 03, 1992 & 0748 & 61 & 27.1 & 3.4 & 22.3 \\
\hline May 22, 1992 & 0849 & 19 & 21.9 & 3.6 & 21.6 & Jul 06, 1992 & 1759 & 64 & 32.9 & 6.6 & 22.5 \\
\hline May 25, 1992 & 1753 & 22 & 30.3 & 5.2 & 25.0 & Jul 07, 1992 & 0756 & 65 & 25.5 & 2.7 & 21.8 \\
\hline May 26, 1992 & 0837 & 23 & 24.2 & 3.1 & 20.8 & Jul 09, 1992 & 1752 & 67 & 29.7 & 4.5 & 26.2 \\
\hline May 28, 1992 & 1733 & 25 & 33.4 & 5.1 & 25.5 & Jul 10, 1992 & 0752 & 68 & 25.7 & 4.4 & 22.6 \\
\hline May 29, 1992 & 0842 & 26 & 33.4 & 8.6 & 22.5 & Jul 13, 1992 & 1805 & 71 & 44.5 & 16.6 & 22.9 \\
\hline Jun 01, 1992 & 1744 & 29 & 28.3 & 4.4 & 25.7 & Jul 14, 1992 & 0753 & 72 & 22.9 & 4.5 & 22.0 \\
\hline Jun 02, 1992 & 0829 & 30 & 29.3 & 2.9 & 22.8 & Jul 16, 1992 & 1755 & 74 & 49.0 & 7.7 & 25.4 \\
\hline Jun 04, 1992 & 1750 & 32 & 31.7 & 3.1 & 30.0 & Jul 17, 1992 & 0754 & 75 & 26.2 & 4.4 & 23.1 \\
\hline Jun 05, 1992 & 0827 & 33 & 32.1 & 3.7 & 23.8 & Jul 20, 1992 & 1753 & 78 & 36.7 & 6.5 & 29.0 \\
\hline Jun 08, 1992 & 1748 & 36 & 41.0 & 4.1 & 29.1 & Jul 21, 1992 & 0753 & 79 & 33.2 & 6.7 & 25.7 \\
\hline Jun 09, 1992 & 0747 & 37 & 46.5 & 4.5 & 23.8 & Jul 23, 1992 & 1744 & 81 & 41.1 & 6.6 & 28.7 \\
\hline Jun 11,1992 & 1750 & 39 & 63.5 & 5.3 & 30.4 & Jul 24, 1992 & 0752 & 82 & 41.1 & 13.6 & 25.0 \\
\hline Jun 12, 1992 & 0755 & 40 & 61.6 & 5.2 & 23.4 & Jul 27, 1992 & 1758 & 85 & 53.7 & 7.2 & 28.7 \\
\hline Jun 15,1992 & 1748 & 43 & 33.0 & 2.4 & 25.9 & Jul 28,1992 & 0752 & 86 & 49.6 & 6.4 & 26.0 \\
\hline Jun 16, 1992 & 0755 & 44 & 32.6 & 3.1 & 23.5 & Jul 30, 1992 & 1752 & 88 & 73.0 & 12.0 & 29.0 \\
\hline Jun 18, 1992 & 1750 & 46 & 34.1 & 6.5 & 23.8 & Jul 31, 1992 & 0750 & 89 & 35.4 & 5.6 & 26.0 \\
\hline Jun 19,1992 & 0747 & 47 & 28.1 & 3.1 & 21.5 & Aug 03, 1992 & 1746 & 92 & 29.8 & 4.5 & 25.9 \\
\hline Jun 22, 1992 & 1800 & 50 & 36.9 & 4.7 & 27.9 & Aug 04, 1992 & 0759 & 93 & 32.9 & 2.9 & 24.9 \\
\hline Jun 23, 1992 & 0752 & 51 & 24.4 & 2.3 & 24.0 & Aug 06, 1992 & 1752 & 95 & 46.2 & 14.0 & 26.1 \\
\hline Jun 25, 1992 & 1758 & 53 & 25.2 & 2.8 & 21.1 & Aug 07, 1992 & 0800 & 96 & 32.1 & 7.4 & 24.6 \\
\hline Jun 26, 1992 & 0755 & 54 & 23.4 & 3.7 & 20.0 & Aug 10,1992 & 1808 & 99 & 50.4 & 23.2 & 28.9 \\
\hline \multirow[t]{5}{*}{ Jun 29, 1992} & 1759 & 57 & 25.5 & 3.7 & 22.9 & Aug 11,1992 & 0759 & 100 & 36.5 & 11.8 & 26.3 \\
\hline & & & & & & Aug 13, 1992 & 1753 & 102 & 30.4 & 1.1 & 26.9 \\
\hline & & & & & & Aug 14, 1992 & 0751 & 103 & 24.3 & 2.6 & 24.8 \\
\hline & & & & & & Aug 17,1992 & 1748 & 106 & 26.8 & 8.7 & 23.6 \\
\hline & & & & & & Aug 18, 1992 & 0802 & 107 & 31.0 & 8.3 & 22.9 \\
\hline May 17,1993 & 0407 & 14 & 13.9 & 2.7 & 19.6 & Jul 08, 1993 & 0907 & 66 & 44.2 & 4.2 & 25.3 \\
\hline May 18, 1993 & 1901 & 15 & 20.3 & 7.0 & 23.0 & Jul 09, 1993 & 2302 & 67 & 43.1 & 3.8 & 28.2 \\
\hline May 20, 1993 & 0906 & 17 & 16.8 & 7.2 & 19.8 & Jul 12, 1993 & 0406 & 70 & 53.2 & 5.8 & 26.2 \\
\hline May 21, 1993 & 2302 & 18 & 19.1 & 3.4 & 23.7 & Jul 13, 1993 & 1902 & 71 & 63.3 & 13.2 & 28.6 \\
\hline May 24, 1993 & 0410 & 21 & 30.0 & 3.7 & 21.8 & Jul 15, 1993 & 0909 & 73 & 57.1 & 4.8 & 26.6 \\
\hline May 25, 1993 & 1905 & 22 & 45.1 & 7.6 & 29.7 & Jul 16, 1993 & 2302 & 74 & 52.1 & 6.7 & 26.6 \\
\hline May 27, 1993 & 0903 & 24 & 34.8 & 2.8 & 23.4 & Jul 19, 1993 & 0416 & 77 & 51.9 & 4.9 & 26.6 \\
\hline May 28, 1993 & 2301 & 26 & 43.4 & 3.4 & 26.8 & Jul 20, 1993 & 1901 & 78 & 48.3 & 5.7 & 26.4 \\
\hline May 31,1993 & 0441 & 28 & 39.2 & 2.9 & 23.7 & Jul 22, 1993 & 0807 & 80 & 51.8 & 14.5 & 24.0 \\
\hline May 01, 1993 & 1908 & 29 & 44.2 & 2.7 & 29.5 & Jul 23, 1993 & 2302 & 81 & 44.1 & 4.4 & 26.7 \\
\hline Jun 03, 1993 & 0906 & 31 & 36.6 & 2.8 & 22.6 & Jul 26, 1993 & 0410 & 84 & 41.8 & 6.2 & 26.7 \\
\hline Jun 04, 1993 & 2304 & 32 & 42.5 & 1.7 & 26.5 & Jul 27, 1993 & 1906 & 85 & 52.0 & 6.2 & 28.0 \\
\hline Jun 07, 1993 & 0434 & 35 & 45.8 & 2.7 & 23.9 & Jul 29, 1993 & 0909 & 87 & 38.0 & 7.8 & 26.1 \\
\hline Jun 08, 1993 & 1849 & 36 & 62.4 & 5.9 & 29.5 & Jul 30, 1993 & 2309 & 88 & 42.6 & 8.9 & 26.2 \\
\hline Jun 10,1993 & 0859 & 38 & 45.9 & 3.7 & 24.2 & Aug 02, 1993 & 0408 & 91 & 36.8 & 5.6 & 24.8 \\
\hline Jun 11, 1993 & 2259 & 39 & 46.6 & 2.8 & 24.4 & Aug 03, 1993 & 1854 & 92 & 33.5 & 7.2 & 27.2 \\
\hline Jun 14,1993 & 0408 & 42 & 49.9 & 3.2 & 23.0 & Aug 05, 1993 & 0900 & 94 & 50.8 & 11.3 & 26.0 \\
\hline Jun 15, 1993 & 1903 & 43 & 38.8 & 4.9 & 29.5 & Aug 06, 1993 & 2328 & 95 & 34.1 & 8.3 & 28.2 \\
\hline Jun 17,1993 & 0905 & 45 & 37.4 & 4.1 & 24.8 & Aug 09, 1993 & 0405 & 98 & 28.4 & 5.4 & 26.1 \\
\hline Jun 18,1993 & 2303 & 46 & 32.9 & 2.3 & 25.0 & Aug 10, 1993 & 1857 & 99 & 37.5 & 4.2 & 24.4 \\
\hline
\end{tabular}


Table 1 continued

\begin{tabular}{|c|c|c|c|c|c|c|c|c|c|c|c|}
\hline Date & Time & $\begin{array}{l}\text { Days } \\
\text { After } \\
\text { Trans- } \\
\text { plant }\end{array}$ & Flux & SE & $\begin{array}{l}T \text {-soil, } \\
{ }^{\circ} \mathrm{C}\end{array}$ & Date & Time & $\begin{array}{l}\text { Days } \\
\text { After } \\
\text { Trans- } \\
\text { plant }\end{array}$ & Flux & SE & $\begin{array}{l}T \text {-soil, } \\
{ }^{\circ} \mathrm{C}\end{array}$ \\
\hline Jun 21, 1993 & 0409 & 49 & 38.5 & 2.2 & 24.0 & Aug 12, 1993 & 0858 & 101 & 32.2 & 6.4 & 24.1 \\
\hline Jun 22,1993 & 1907 & 50 & 41.1 & 1.7 & 29.2 & Aug 13, 1993 & 2310 & 102 & 29.7 & 4.7 & 26.2 \\
\hline Jun 24,1993 & 0900 & 52 & 30.6 & 4.6 & 24.9 & Aug 16,1993 & 0418 & 105 & 20.9 & 1.6 & 23.0 \\
\hline Jun 25,1993 & 2303 & 54 & 28.1 & 4.8 & 28.7 & Aug 17, 1993 & 1904 & 106 & 41.6 & 7.3 & 26.5 \\
\hline Jun 28,1993 & 0410 & 56 & 27.8 & 4.6 & 24.0 & Aug 19,1993 & 0904 & 108 & 20.4 & 2.1 & 23.8 \\
\hline Jun 29,1993 & 1907 & 57 & 28.2 & 3.3 & 28.7 & Aug 20, 1993 & 2303 & 110 & 21.2 & 3.1 & 24.7 \\
\hline Jul 01, 1993 & 0907 & 59 & 27.8 & 3.8 & 24.7 & Aug 23, 1993 & 0414 & 112 & 29.6 & 6.0 & 24.6 \\
\hline Jul 02,1993 & 2306 & 60 & 27.5 & 3.1 & 23.2 & Aug 24, 1993 & 1903 & 113 & 16.4 & 4.7 & 24.9 \\
\hline Jul 05, 1993 & 0433 & 63 & 33.8 & 3.8 & 25.1 & Aug 26, 1993 & 0908 & 115 & 27.6 & 8.4 & 22.0 \\
\hline Jul 06, 1993 & 1850 & 64 & 34.7 & 4.0 & 26.3 & & & & & & \\
\hline May 21, 1994 & 1416 & 17 & 15.2 & 3.7 & 24.2 & Jul 04, 1994 & 0411 & 61 & 38.9 & 1.8 & 24.4 \\
\hline May 23,1894 & 0832 & 19 & 16.8 & 4.6 & 22.1 & Jul 05, 1994 & 1906 & 62 & 55.3 & 6.1 & 28.4 \\
\hline May 24, 1994 & 1918 & 20 & 22.0 & 4.7 & 25.3 & Jul 07, 1994 & 0809 & 64 & 46.4 & 3.1 & 24.0 \\
\hline May 26,1994 & 0815 & 22 & 18.7 & 3.4 & 22.4 & Jul 08, 1994 & 2306 & 66 & 45.6 & 3.6 & 26.4 \\
\hline May 27, 1994 & 2307 & 24 & 19.0 & 2.4 & 23.4 & Jul 11, 1994 & 0411 & 68 & 60.9 & 4.2 & 23.8 \\
\hline May 30, 1994 & 0421 & 26 & 23.5 & 2.8 & 23.1 & Jul 12, 1994 & 1907 & 69 & 49.3 & 3.0 & 29.1 \\
\hline May 31,1994 & 1909 & 27 & 28.3 & 2.6 & 30.4 & Jul 14, 1994 & 0805 & 71 & 57.7 & 5.0 & 25.9 \\
\hline Jun 02,1994 & 0820 & 29 & 27.9 & 2.3 & 24.5 & Jul 15,1994 & 2306 & 73 & 50.3 & 4.0 & 26.5 \\
\hline Jun 04, 1994 & 2306 & 30 & 24.7 & 2.0 & 23.2 & Jul 18, 1994 & 0417 & 75 & 56.1 & 9.2 & 24.8 \\
\hline Jun 06, 1994 & 0412 & 33 & 25.3 & 2.2 & 25.3 & Jul 19, 1994 & 1906 & 76 & 50.2 & 3.4 & 27.0 \\
\hline Jun 07, 1994 & 1911 & 34 & 23.6 & 1.1 & 24.8 & Jul 21, 1994 & 0810 & 78 & 38.2 & 6.3 & 26.4 \\
\hline Jun 09,1994 & 0804 & 36 & 22.8 & 1.2 & 26.0 & Jul 22, 1994 & 2259 & 79 & 64.7 & 14.3 & 27.2 \\
\hline Jun 10,1994 & 2305 & 38 & 29.2 & 1.7 & 28.6 & Jul 25, 1994 & 0410 & 82 & 71.5 & 18.0 & 26.0 \\
\hline Iun 13,1994 & 0414 & 40 & 32.7 & 1.8 & 27.3 & Iul 26, 1994 & 1906 & 83 & 44.2 & 7.9 & 28.8 \\
\hline Jun 14,1994 & 1906 & 41 & 34.6 & 1.6 & 27.0 & Jul 28, 1994 & 0811 & 85 & 26.2 & 4.5 & 26.1 \\
\hline Jun 16,1994 & 0817 & 43 & 310 & 1.3 & 24.7 & Jul 29, 1994 & 2303 & 86 & 47.1 & 3.5 & 26.4 \\
\hline Jun 17,1994 & 2308 & 45 & 29.4 & 1.2 & 23.9 & Aug 01, 1994 & 0405 & 89 & 45.1 & 4.8 & 26.0 \\
\hline Jun 20,1994 & 0419 & 47 & 28.1 & 0.9 & 21.0 & Aug 02, 1994 & 1914 & 90 & 54.3 & 5.1 & 29.7 \\
\hline Jun 21, 1994 & 1906 & 48 & 30.3 & 2.3 & 24.5 & Aug 04, 1994 & 0810 & 92 & 28.9 & 3.1 & 26.8 \\
\hline Jun 23,1994 & 0805 & 50 & 31.4 & 2.4 & 23.5 & Aug 05, 1994 & 2302 & 93 & 56.3 & 3.8 & 29.5 \\
\hline Jun 24, 1994 & 2306 & 52 & 30.7 & 1.4 & 23.0 & Aug 08, 1994 & 0410 & 96 & 43.3 & 3.7 & 26.7 \\
\hline Jun 27,1994 & 0409 & 54 & 35.8 & 1.3 & 23.5 & Aug 09, 1994 & 1903 & 97 & 41.8 & 6.4 & 30.5 \\
\hline Jun 28, 1994 & 1908 & 55 & 41.7 & 4.6 & 27.8 & Aug 11, 1994 & 0806 & 99 & 44.2 & 5.0 & 27.8 \\
\hline Jun 30,1994 & 0821 & 57 & 37.0 & 1.4 & 22.9 & Aug 12, 1994 & 2258 & 100 & 43.5 & 4.9 & 28.7 \\
\hline \multirow[t]{2}{*}{ Jul 01, 1994} & 2305 & 58 & 41.6 & 2.9 & 23.7 & Aug 15, 1994 & 0406 & 103 & 36.7 & 1.7 & 24.7 \\
\hline & & & & & & Aug 16, 1994 & 1906 & 104 & 48 & 4.7 & 30.2 \\
\hline
\end{tabular}

Flux values are in units of $\mathrm{mg} / \mathrm{m}^{2} / \mathrm{h}$. The data are averaged over up to 24 plots. SE, standard error $\left(\mathrm{mg} / \mathrm{m}^{2} / \mathrm{h}\right)$.

Province of China (latitude $29.5^{\circ} \mathrm{N}$, longitude $106.7^{\circ} \mathrm{E}$ ). Rice has been grown in this area for hundreds of years.

The region lies at the western edge of the monsoon belt characterized by warm, wet summers and cool, arid winters. Tall mountains to the north and west protect the basin from Arctic weather patterns, making it warmer in winter than other locations in China at the same latitude. Average total precipitation is about 900 to $1000 \mathrm{~mm} / \mathrm{yr}$; mean temperatures are about $26^{\circ} \mathrm{C}$ in July and $5^{\circ} \mathrm{C}$ in January. There are nearly 300 frost-free days per year, which allows two to three crops to be grown in rotation. With its high humidity and cool surrounding mountains, the basin is famous for its fogs and has the lowest total solar radiation in China, with an annual average of less than $30 \%$ sunshine but up to $40 \%$ during summer [ $Z$ hao, 1986; $X u, 1991$ ].

The traditional method of soil classification in China is by color. The soil around $\mathrm{Tu} \mathrm{Zu}$ is classified as "purple soil," characteristic of the Sichuan basin. It is formed from Cretaceous purple shales and red sandstone in the forests and washed down into the plain [Zhao, 1986; USSR Academy of Sciences, 1969]. The top soil at the Tu $\mathrm{Zu}$ site has been changed by continuous inundation and rice farming practices. Chemical and physical characterizations of the soil are given in Table 3.

The map of the fields and sampling locations is shown in Figure 1. The region has low hills and valleys. Our fields were located in one such valley with hills some 10 to $30 \mathrm{~m}$ high on three sides. These topographical conditions create a microclimate that is somewhat different from the prevailing conditions of the region. No high winds were recorded, for instance, and runoff occasionally caused high water in the fields. Under normal conditions, water level is kept at about $5 \mathrm{~cm}$ depth, but it is nearly drained before broadcast fertilization. The water is supplied by summer rains and the canals of the Dujiangyan irrigation system. 
Table 2a. Agronomic Meta Data: Number of Plants per Plot

\begin{tabular}{|c|c|c|c|c|c|c|c|c|}
\hline \multirow[b]{2}{*}{ Field } & \multirow[b]{2}{*}{$\begin{array}{l}\text { Sampling } \\
\text { Point }\end{array}$} & \multicolumn{7}{|c|}{ Year } \\
\hline & & 1988 & 1989 & 1990 & 1991 & 1992 & 1993 & 1994 \\
\hline \multirow[t]{6}{*}{1} & 1 & $1-2$ & 4 & 4 & not & & & \\
\hline & 2 & $1-2$ & 3 & 4 & sampled & & 0 & \\
\hline & 3 & $1-2$ & 4 & 4 & & 0 & 1 & \\
\hline & 4 & $1-2$ & 2 & 4 & & 1 & 1 & 0 \\
\hline & 5 & $1-2$ & 2 & 4 & & 4 & 4 & 1 \\
\hline & 6 & $1-2$ & 4 & 4 & & 4 & 4 & 4 \\
\hline \multirow[t]{6}{*}{2} & 1 & $1-2$ & 4 & 4 & 4 & 0 & 0 & 0 \\
\hline & 2 & $1-2$ & 2 & 4 & 4 & 1 & 0 & 1 \\
\hline & 3 & $1-2$ & 3 & 4 & 4 & 4 & 1 & \\
\hline & 4 & $1-2$ & 2 & 4 & 4 & 4 & 4 & 4 \\
\hline & 5 & $1-2$ & 3 & 4 & 4 & & 4 & \\
\hline & 6 & $1-2$ & 4 & 4 & 4 & & & \\
\hline \multirow[t]{6}{*}{3} & 1 & $3-4$ & 2 & 4 & 4 & 0 & 0 & \\
\hline & 2 & $3-4$ & 4 & 4 & 4 & & & \\
\hline & 3 & $3-4$ & 3 & 4 & 4 & 1 & 0 & \\
\hline & 4 & $3-4$ & 4 & 4 & 4 & & 1 & 1 \\
\hline & 5 & $3-4$ & 3 & 4 & 4 & 4 & 4 & 4 \\
\hline & 6 & $3-4$ & 2 & 3 & 4 & 4 & 4 & \\
\hline \multirow[t]{6}{*}{4} & 1 & $3-4$ & 2 & 4 & not & 0 & 0 & 1 \\
\hline & 2 & $3-4$ & 2 & 2 & sampled & 1 & 0 & 2 \\
\hline & 3 & $3-4$ & 3 & 2 & & & 1 & \\
\hline & 4 & $3-4$ & 2 & 4 & & & 1 & 4 \\
\hline & 5 & $3-4$ & 2 & 4 & & 4 & 4 & \\
\hline & 6 & $3-4$ & 4 & 4 & & & 4 & \\
\hline \multirow[t]{2}{*}{5} & 1 & & & & & 4 & & \\
\hline & 2 & & & & & 4 & & \\
\hline
\end{tabular}

There were no local sources of pollution at the site. The supply road passing near the fields was about $300 \mathrm{~m}$ away with a hill in between. The farmer's house was located near the fields, but the fields we selected were some distance downslope from the house. Occasional pollution from Leshan City may have come to the site, but its effect is not important for this study.

The fields we studied in $\mathrm{Tu} \mathrm{Zu}$ grew one rice crop each year rotated with oil seed for the rest of the year. The oilseed crop is harvested in early spring, and the stubble is incorporated by plowing with oxen. Rice is planted in seedling beds toward the end of March. It is transplanted in the fields 3-4 weeks later. Harvests are usually in late August. We took our samples between the rice transplanting and harvest dates (see Table 2).

\subsection{Field and Experimental Methods}

This is fundamentally an observational study. It was designed to quantify decadal-scale methane emission rates from the fields we were studying and to identify the factors that affect emissions. An important principle was to study the normal spatial and interannual variability of methane emission rates by observing the fields under the prevailing agricultural practices. We exercised no control on the management of the rice fields. So, during the years of the experiment the farmer used different cultivars as available in the region and various amounts of available fertilizers.

The experimental design was developed to support an observational study and was flexible enough to detect and adapt to new observations and unexpected results. It includes the following four interrelated elements: (1) spatial and temporal sampling strategy; (2) sampling practices and design of field sampling equipment; (3) laboratory measurements of methane; and (4) simultaneous ancillary measurements and meta data to study the factors that affect methane emissions. These elements are described here and certain implications or additional theoretical investigations are discussed in subsequent papers. The four elements are optimized for the measurement of methane flux as best as it can be done within logistical and instrumental constraints. The design of this experiment is more or less the standard method used in all similar studies.

2.2.1. Spatial and temporal sampling strategy. The farmers usually plant two seedlings (or sometimes even three) in the same location. As these plants mature, they tiller and produce many stems. We refer to each of these "clumps" as a plant. We assumed that each plant is the main source of methane emission in the field. Smaller amounts are emitted from the surrounding water. Our working hypothesis was that there were two forms of spatial variability inherent in the system we were studying, one that affected emissions within a rice field and the other that could cause systematic differences of emissions between fields. Each field is treated uniformly and planted with uniform spacing among plants. Fertilizers are uniformly spread over the field. Here variability within the field arises from random variability of controlling processes at each plant. So each plant is assumed to emit methane at an average rate characteristic of the field with random variability superimposed, representing microscale differences in the environment. Spatial variability of methane 


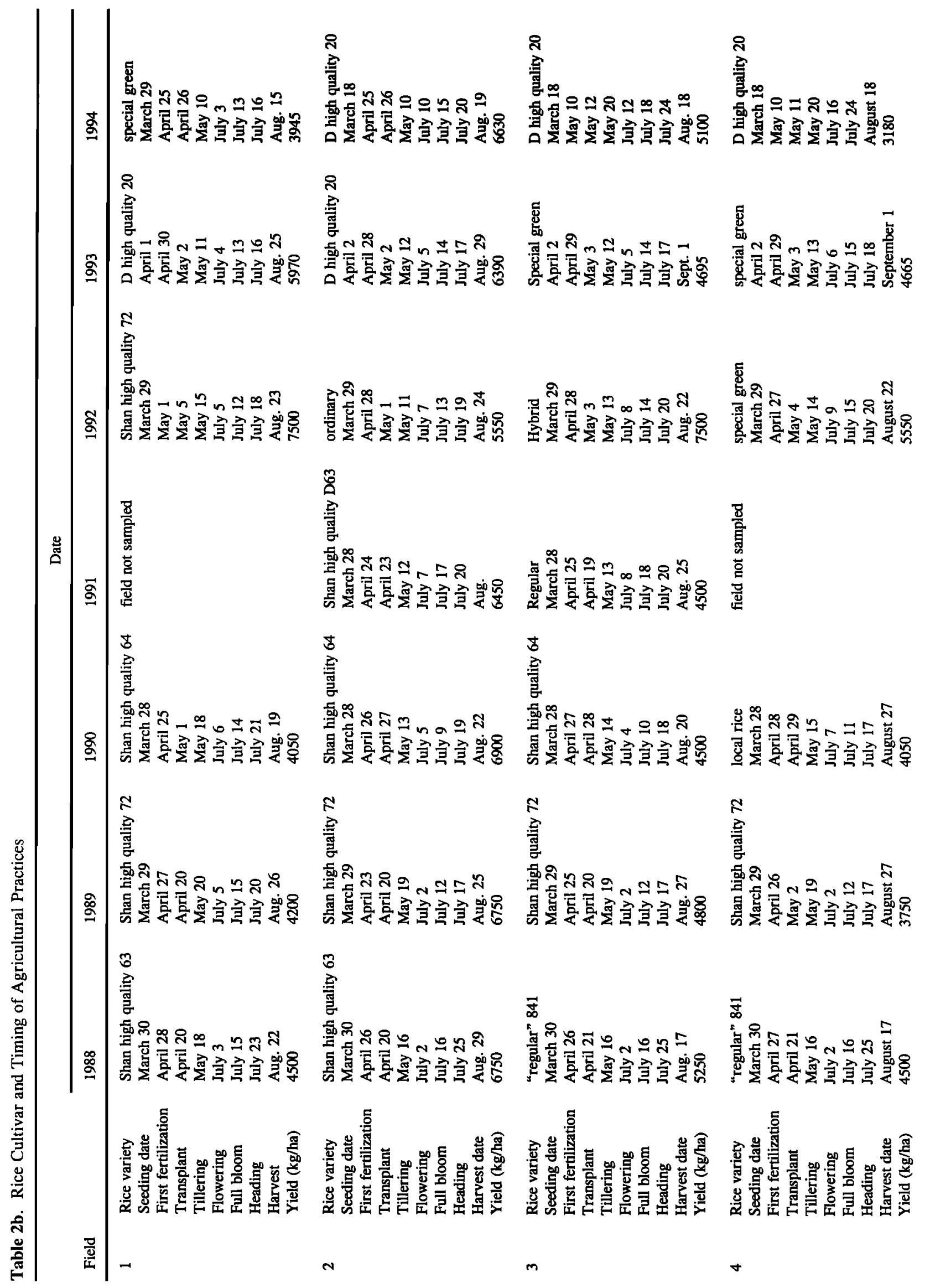


emissions within the field is then assumed to be represented by the variability among plants. For this reason, random placement of the chambers is not needed. Since the spatial variability is driven by the variability of emissions from individual plants, spatial variability is equally well measured by many replicates of single plant fluxes. We took six replicates within a field to address this small scale random variability. The first year results made it clear that six replicates were enough and we could afford to reduce this number and still preserve the precision of the data to satisfy our needs (see Khalil et al., this issue, a).

The cross-field variability could be thought of as more systematic than random. It addresses the fact that a different cultivar could be planted in an adjacent field, or that the previous crop in one field is different from the other field, leading to a different methane emission rate, or that the amount of fertilizer applied per hectare is different in one field relative to the other. These sorts of systematic differences between the treatment of side-by-side fields could cause systematic differences in the seasonally averaged flux from one field relative to another. We chose four fields close to each other for assessing this variability. The issue of local spatial variability is addressed by replicates of emissions within a field with assumed uniform treatment with respect to all relevant variables, and the cross-field variability is addressed by replicates of fields. The same plots and fields were used every year from 1988 to 1994 . In some years, all six plots or all four fields could not be sampled.

2.2.2. Sampling practices and design of field sampling equipment. The plots were set up along the walkways between fields or to the sides of the fields. The plots were positioned 1-2 $m$ into the fields to avoid possible edge effects on emissions. While the fields were being prepared for planting, we installed wooden boardwalks from the edge of the field to the sampling location. An aluminum frame was installed at the end of the boardwalk and kept in place from before the time that the rice was planted until after it was harvested. The frame had a collar that penetrated into the top soil, and it was attached to wooden stakes that penetrated into the hard clay below. These actions were designed to prevent the soil from being disturbed during the sampling processes. Disturbance or agitation of the soil can cause visible bubbling and release of methane that could contaminate the samples and invalidate the flux measurement. The top of the frame had a groove into which we could place our chambers and fill it (the groove) with water to seal the system.

The dimensions of the square frame were $23.4 \mathrm{~cm}$ on the inside and $31 \mathrm{~cm}$ on the outside. The area of the rice fields that was exposed inside the chambers was $547.6 \mathrm{~cm}^{2}$. The collar that penetrated into the top soil was $3 \mathrm{~cm}$ deep so that the entire vertical extent of the base (below soil to the top) was $6.3 \mathrm{~cm}$. The chambers we used were translucent polyethylene $0.3175 \mathrm{~cm}$ thick. The base was a square $28.6 \mathrm{~cm}$ in length (inside) and the heights were $22.9 \mathrm{~cm}, 45.7 \mathrm{~cm}, 68.6 \mathrm{~cm}$, and $88.9 \mathrm{~cm}$, representing internal volumes of $5,10,15$, and 20 gallons. As the rice plants grew, taller and taller chambers had to be used. Although a single large-sized chamber could have been used throughout, the use of graded volumes provided greater sensitivity for detecting low fluxes in the early stages of growth. The main reason for choosing these chambers was that they were of a convenient size to be carried back and forth from the sampling sites and to be shipped from our laboratory to China. Experiments conducted early on showed no detectable gradients of concentrations within the chambers when placed on the rice fields. Based on these results and the fact that these chambers 


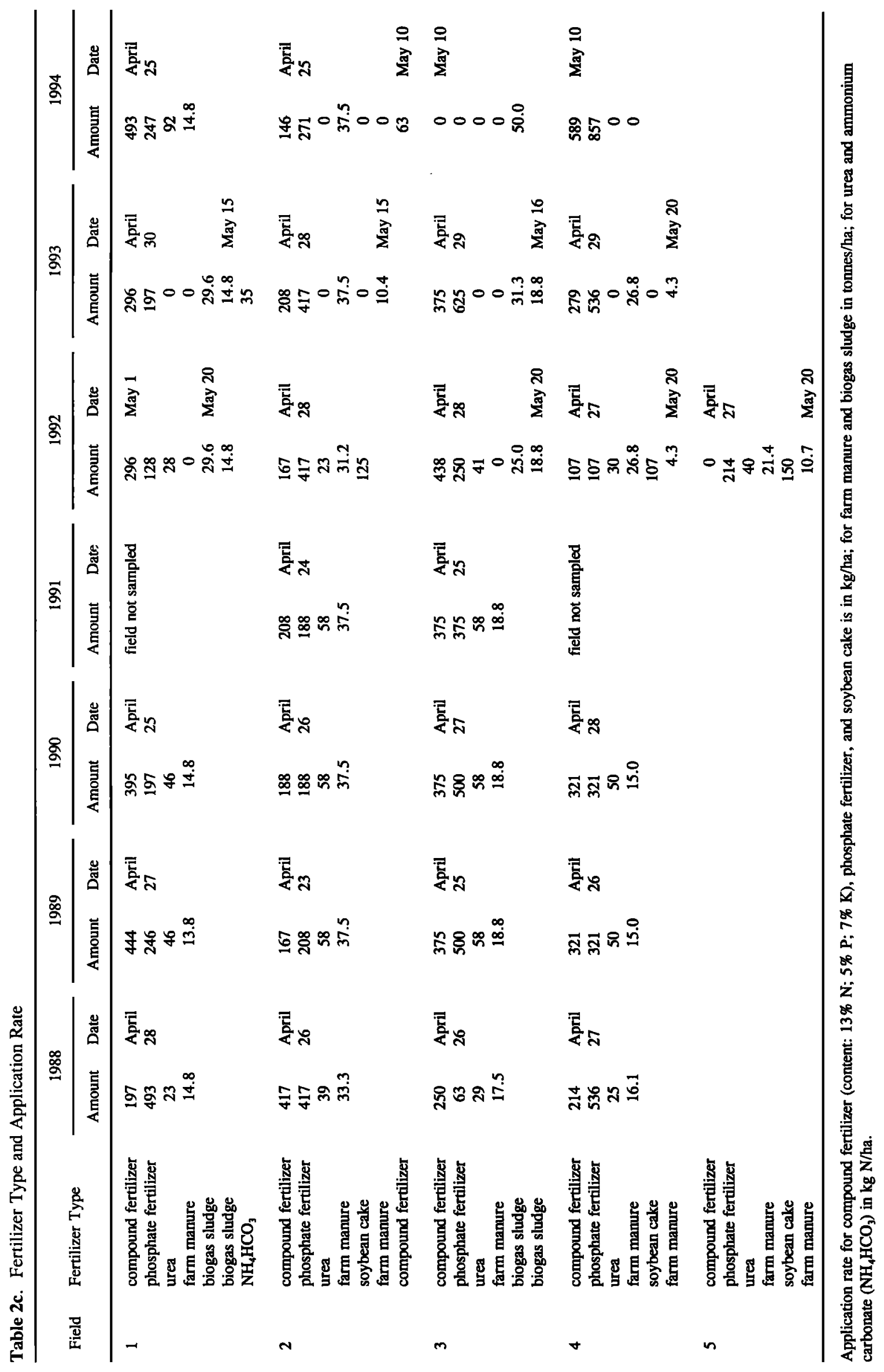


Table 3. Physical and Chemical Characteristics of the Soil at Tu Zu

\begin{tabular}{lcc}
\hline \hline & Size, $\mathrm{mm}$ & Value \\
\hline Sand & $1.0-0.05$ & $78.5 \%$ \\
Silt & $0.05-0.002$ & $11.9 \%$ \\
Clay & $<0.002$ & $9.6 \%$ \\
Organic matter & & $1.57 \%$ \\
$\mathrm{pH}$ & & 5.0 \\
\hline Element & Total & Available, ppm \\
\hline $\mathrm{N}$ & $0.115 \%$ & 114.6 \\
$\mathrm{P}$ & $0.011 \%$ & 3.1 \\
$\mathrm{~K}$ & $1.02 \%$ & 8 \\
$\mathrm{Ca}$ & $136 \mathrm{ppm}$ & \\
$\mathrm{Mg}$ & $4167 \mathrm{ppm}$ & \\
$\mathrm{Cu}$ & $26.7 \mathrm{ppm}$ & 1.1 \\
$\mathrm{Fe}$ & $8525 \mathrm{ppm}$ & 690 \\
$\mathrm{Zn}$ & $39.9 \mathrm{ppm}$ & 1.5 \\
$\mathrm{Mn}$ & $62.5 \mathrm{ppm}$ & 32.5 \\
\hline \hline
\end{tabular}

Organic matter determined using dichromate method $\left(\mathrm{K}_{2} \mathrm{Cr}_{2} \mathrm{O}_{7}\right)$; the conversion factor to organic carbon is usually taken to be 2 ; total $\mathrm{N}$ and available $\mathrm{N}$ by digestion and distillation; total $\mathrm{P}$ was measured with a colorimeter; $0.03 \mathrm{M} \mathrm{NH}_{4} \mathrm{~F}-0.1 \mathrm{HCl}$ solution was used to extract available $\mathrm{P}$; atomic absorption spectrophotometer was used to measure total $\mathrm{Cu}, \mathrm{Fe}$, $\mathrm{Mn}, \mathrm{Ca}, \mathrm{Mg}$, and $\mathrm{K} ; 0.1 \mathrm{M} \mathrm{HCl}$ was used to extract available $\mathrm{Cu}, \mathrm{Fe}, \mathrm{Zn}$, and $\mathrm{Mn}$. These characteristics are representative of all fields.

were small and thus allowed good thermal mixing due to the warm surface enclosed, no fan was installed.

The chambers had a sampling port that consisted of a Teflon tube about $1.5 \mathrm{~m}$ long, attached at one end to the top of the chamber with a stainless steel assembly and equipped with a silicone rubber septum at the other end. A stainless steel tube extended below the sampling port and into the chamber. This ensured that samples were collected from the middle of the chamber. Samples were collected through the septum using 10 $\mathrm{mL}$ glass syringes with a 22 gauge needle. Tests showed that the concentrations of methane did not change in the syringes over several days, which is much longer than the actual time between sampling and sample analysis [Husin et al., 1995].

In the last years of the experiment, we used large chambers in addition to the small chambers described here. The large chambers were constructed at our laboratory from readily available materials. The dimensions were base $140 \mathrm{~cm} \mathrm{x} 140 \mathrm{~cm}$ and heights $57 \mathrm{~cm}$ and $114 \mathrm{~cm}$. A fan is essential in these chambers because of the large volume within which there can be substantial gradients during the sampling times involved. These chambers were clear polyethylene plastic sheets supported by a frame made of $1.27 \mathrm{~cm}$ diameter polyvinylchloride (PVC) tubing. The sampling port arrangements were as before. The permanent base was a 10-cm (4-inch) PVC drain pipe cut longitudinally and installed in the rice field prior to the planting of rice.

2.2.2.1. Sampling protocol: The following sampling and analysis procedures were followed: (1) The chamber was placed gently onto the aluminum groove. Every precaution was taken to prevent agitation of the soil or plants to avoid spurious emissions of methane. (2) If the water level was below the top of the base, the groove was filled with paddy water. This makes an air tight seal between the surface of the rice field and the chamber. (3) Four samples were drawn 3 min apart, using glass syringes. After the needle was inserted into the septum, the syringe was flushed with the air from inside the chamber before a sample was taken. The total time that the chamber remained on the rice plants is therefore 12-15 min. We kept this time as short as possible so as to minimize the disturbance to the plants. The short time also prevented any substantial temperature increases inside the chambers during the course of the experiment. (4) The syringes were marked and stored for analysis. Readings of the soil and air temperatures and the water level were taken at each plot. (5) At each field, duplicate syringe samples of ambient air were taken, and the wind speed and direction and sky conditions were recorded. The height of the plants was measured once a week. This process was repeated for all the fields and plots.

2.2.2.2. Sampling frequency: A sampling cycle was adopted that repeated every week. All plots were sampled in the morning of Monday. This took about 2-3 hours. On the next day, samples were collected from all plots in the late afternoon. This gave us a measure of the diumal pattern of emissions. The third day was spent in analyzing the samples and recording the data on data sheets. This process was repeated for the fourth, fifth, and sixth days. The seventh day, Sunday, was a break, then the process started over for the next week. This constitutes four sample days per week. In later years, in response to a need for a better understanding of diumal patterns, the sampling frequency was modified to include nighttime measurements. For 1993 and 1994 sampling was done during each of the four quarters of the day (0200-0800, 0800-1400, 1400-2000, 2000-0200 hours). On the

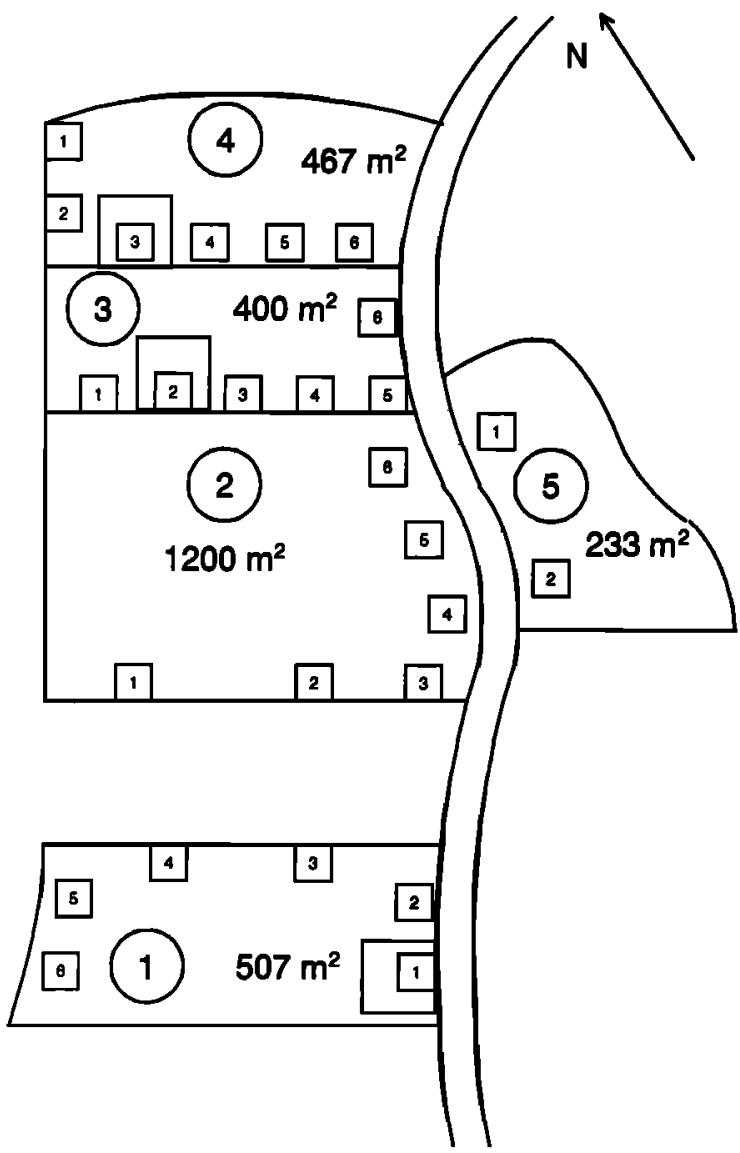

Figure 1. The layout of the fields at $\mathrm{Tu} \mathrm{Zu}$, China, where the experiment was done. The same fields and plot locations were used every year from 1988 to 1994 . The area of the fields is given in $\mathrm{m}^{2}$. At the right edge of the fields is a walkway and between fields there were dikes. Between fields 1 and 2 and beyond field 1 there were other rice fields. Beyond field 4 and to both sides there were hills separating other rice fields from this area. The small squares represent the original plots with small chambers; the large squares are the large chambers (not to scale). 
first day, samples were collected during the first quarter (00000600); on the second day, in the third quarter; no samples on the third day; samples in the second quarter on the fourth day; no samples on the fifth day; samples in the fourth quarter on the sixth day; and a break on the seventh day. The actual sampling times were around $0400,0900,1900$, and 2400 . The days when samples are not collected were spent on the analyses. The syringes were recycled as the analytical measurements were completed. The samples were stored for no more than a day or two. The sampling frequency was chosen as close to what was needed for estimates of diurnal variations, and was still compatible with what the field personnel were willing to carry out in the middle of the night. Further analysis of the sampling frequency is given in another paper [Khalil et al., this issue (a)].

2.2.3. Laboratory measurements of methane (sample analysis). Samples were analyzed using a Gow-Mac Model 69350 gas chromatograph equipped with a flame ionization detector (GC/FID). This gas chromatograph was operated in a rented facility near the rice fields. The gas sample was injected through a 2-mL sampling loop and separated on a porapak $\mathrm{N}$ column (5-ft long $\times 1 / 8$-inch outside diameter), with nitrogen as a carrier gas. The chromatographic operating conditions were column temperature $40^{\circ} \mathrm{C}$, detector temperature $140^{\circ} \mathrm{C}$, carrier gas flow rate $30 \mathrm{~mL} / \mathrm{min}$, hydrogen gas flow rate $25 \mathrm{~mL} / \mathrm{min}$, and compressed air flow rate $250-300 \mathrm{~mL} / \mathrm{min}$. High purity grade hydrogen and nitrogen gases were utilized. The gas chromatograph was calibrated to measure methane with high precision at our laboratory where the linearity of the signals was established up to $500 \mathrm{ppmv}$. The lower detection limit of the gas chromatograph was found to be about $9 \mathrm{ppbv}$, and the precision was determined to be about $0.8 \%$. In the field, the gas chromatograph was calibrated after every 5-10 sample runs, using a standard of $1770 \mathrm{ppbv}$ methane in air. The secondary standards used at the field sites in China were calibrated directly against the National Institute of Standards and Technology (NIST) primary standard SRM 1659A, maintained at our laboratory. The concentration of methane was calculated using an HP 3396A integrator connected to the gas chromatograph. The integrator measures the area under the methane chromatographic peak and converts it to a concentration by comparing the peak area to the peak area from an analysis of a standard with known concentration (issues related to the measurements are discussed further by Khalil et al., this issue (a)).

2.2.4. Ancillary measurements and meta data. In addition to the flux measurements, we also took measurements of the environmental conditions and the needed meta data that could reveal the factors controlling methane emissions from rice fields. The environmental data we took at the same time as the flux measurements were: Water level inside the base and outside, air temperature, soil temperature at $5 \mathrm{~cm}$ depth, wind speed and direction, sky cover (for solar radiation), background air concentrations, and height of the rice plants (once a week).

The meta data are the cultivar, number of plants in each chamber, fertilizers used and the mode and timing of application, rice yield from each field, dates for planting seeds, transplanting, reaching tillering stage, blooming, full flowering, fruiting, and harvest. The meta data are included in Table 2.

This part of the experimental design is particularly complicated because it is difficult to know what variables should be measured. And, since we were working with prevailing agricultural practices, we could not control any of these variables. On the other hand, the information we have obtained reflects the impact of each variable on methane emissions when many factors are present simultaneously in an actual rice field, as opposed to an experimental and controlled rice field. This experiment is not optimized to delineate the effect of each factor or its interactions with other factors. The information we can obtain here about this matter is a foundation for new laboratory and field experiments that can be used to study these factors and their interactions. Further discussion of the factors affecting methane emissions as measured in our experiments is given in a companion paper [Khalil et al., this issue (b)].

2.2.5. Exceptions to the standard procedures. The standard procedures are described above. During some years we had to accept departures from these procedures. This was because in some years specific parameters had to be tested requiring changes in procedures, there were occasional instrument failures, and in some years the full sampling could not be implemented because sufficient personnel time could not be purchased. The departures from the standard sampling protocols are noted here. In 1990, the instrument failed during the middle of the growing season, causing loss of data. We believe that the effect of this failure is not substantial for the calculated seasonally averaged fluxes but makes other calculations less certain. In 1991, only two fields were sampled with three plots in each field, constituting only $25 \%$ of the normal sampling protocol. Moreover, we took only three sequential samples for each flux measurement, instead of the usual four. The exposure time was about $9 \mathrm{~min}$. Further analysis of the data show that taking only three measurements over 9 min leads to substantially higher variability of the estimated flux, loss of correlations between measurements taken at adjacent plots and the relationships between emissions and environmental factors. Based on the initial analysis of the data, the practice of taking only three samples per flux measurement was abandoned. Three measurements may in themselves not be the main deficiency of the sampling; instead, it may be that the shorter time over which the flux was measured that contributed to the greater variability (Khalil et al., this issue (a), has a more detailed analysis). Nonetheless, the seasonally averaged data are reliable even though the within-season patterns in the data are uncertain. In 1992, the sampling was extended to 16 plots. Two of the plots were in a new nearby field that was used only this year. There was no apparent difference between the new field (field 5) and the other fields, so data were pooled with field 4 for convenience. Also starting in 1992, we had one plot in each field with no plants, leaving 12 plots with plants. In 1993 and 1994 we increased the number of plots again and in the last year added large chambers, with the smaller chambers inside and outside the large ones. We also added sampling over 4 periods of the day to get a more accurate assessment of the diumal variability and validate the previous data when only morning and late afternoon samples were collected. These modifications have different effects on different types of calculations based on these data. The seasonally averaged emissions from each field or the composite of all fields are not significantly affected. In 1995, the instrument failed after the first month of sampling and circumstances prevented a repair or replacement in time to complete the experiment. The few early data that were obtained in 1995 were found to be unreliable and were discarded from further analysis.

\section{Flux Calculations and Quality Assurance Procedures}

\subsection{Flux Calculations}

The flux of methane is expressed as mg of methane emitted per square meter per hour. This is a commonly used unit for methane emissions from rice fields and gives numbers between 0 and about 200 for all measurements. Based on the experiment described above, the flux is calculated as follows: 


$$
F=\alpha\left[\frac{M}{N_{0}} \rho \frac{V}{A}\right] \frac{d C}{d t}
$$

where $C$ is the measured concentrations in the chamber and $d C / d t$ is the rate of accumulation in ppbv/min. $A$ is the area from which methane is emitted into the chamber (here $0.056 \mathrm{~m}^{2}$ for small chambers and $1.96 \mathrm{~m}^{2}$ for large chambers), $V$ is the volume of the chamber $\left(\mathrm{m}^{3}\right), N_{0}$ is Avogadro's number, $\rho$ is the density of air (molecules $/ \mathrm{m}^{3}$ ), $\alpha$ is a unit conversion factor $=6.0 \times 10^{-5} \mathrm{mg}$ $\mathrm{min} / \mathrm{g}-\mathrm{h}-\mathrm{ppbv}$, and $M$ is the molecular weight of methane $(\mathrm{g} / \mathrm{mol})$. The temperature measured inside the chamber was used to calculate the density of air using the ideal gas law. For the small chambers, $V / A$ is not the same as the height of the chamber because the area from which methane emissions occur is the inside area of the base and not the area of the base of the chamber. The air volume inside the chamber is reduced if there is a lot of water, and increased when there is less, hence the height of the water in the field is also taken into account. In later stages of growth, several percent of the chamber is occupied by the plants, reducing the volume. This effect is expected to be small and is not taken into account. For the large chambers many of these factors are unimportant.

The most important variable in (1) is $d C / d t$, which is derived from the concentration measurements; all other variables are known precisely. We estimated $d C / d t$ by several methods. We chose ordinary linear regression as the most reliable method for our study. We estimated $d C / d t$ by " $b$ " in $C=C_{0}+b t$, and the correlation coefficient between $C$ and $t$ is a measure of the uncertainty in $d C / d t$.

The lower detection limit of the flux by such chambers is inversely related to the height of the chambers. For our smallest chambers, we estimate the lower detection limit is $\sim 0.5 \mathrm{mg} / \mathrm{m}^{2} / \mathrm{h}$ and it is $\sim 1-2 \mathrm{mg} / \mathrm{m}^{2} / \mathrm{h}$ for the taller chambers, including the large chambers used after 1993 [Khalil et al., this issue (a)].

\subsection{Quality Assurance}

Although we took many measurements, not all the experiments were successful. Some of the methods we adopted, of necessity as discussed earlier, contributed to the failure of some measurements. We use two criteria for selecting the experiments we consider to be successful. (1) The square of the correlation coefficient $\left(r^{2}\right)$ for the buildup of methane in the chambers was required to be greater than 0.9 . This criterion has been used by others [Sass et al., 1992]. (2) We required that the time zero value of the regression of concentration with time, $C_{0}$, is greater than the measured background concentration near the field.

The first criterion, $r^{2}>0.9$, is based on the assumption that the flux of methane does not change over the short periods of time involved in the experiment ( $<20 \mathrm{~min})$. The production of methane by biological processes takes place below the soil surface. This region is shielded from rapid changes in environmental conditions by the overlaying water and mud. Since samples were taken only when no work was being done on the field, we believe that rapid changes in flux over 3-min intervals, as in our experiment, should not occur, except as artifacts of the sampling or analytical processes. When such changes of flux are observed, they are reflected in the value of the correlation coefficient. Since we are dealing with only four sequential measurements, an $r^{2}$ of 0.9 is not an overly stringent criterion. By chance $r^{2}$ can be 0.9 or greater with a probability of $2.5 \%$. In 1991 when only three measurements were taken to obtain the flux, the criterion increases to a $10 \%$ probability that accepted accumulation rates can be due to chance. The criterion still allows accumulation profiles that appear nonlinear to the eye.

The second criterion was designed to address a class of anomalous experiments that pass the first criterion. This class consisted of cases where the accumulation rate slows down substantially in time but not enough to reduce $r^{2}$ below 0.9 . The second criterion tests for cases where there may have been a burst of methane in the first 3 min that may represent a disturbance of the system. The concentration of methane in the chamber at time zero $\left(\mathrm{C}_{0}\right)$, as calculated using the regression formula, should be well above the background concentration near the field, since air from over the rice fields mixes into the chamber as it is placed on the base. $C_{0}$ is not directly measured in the experiments as the first sample is taken 3 minutes after the chamber is placed on the base. The methane concentrations over the rice fields are very much higher than near the fields away from the plants, as verified by experiments discussed later. When $C_{0}<C_{\mathrm{b}}$, it implies that the first flux is anomalous relative to the later measurements. This criterion is not stringent, and only few additional experiments are eliminated by its application. In most cases, when this criterion is not met, the first criterion is also violated.

One case when $r^{2}$ would be small is if there was no flux. In that case, the low value of $r^{2}$ is not a reflection of a failed experiment but rather of an undetectably low flux. The use of this criterion, therefore, requires other information so as not to bias the results. In the case at $\mathrm{Tu} \mathrm{Zu}$, there is corroborative evidence of strong flux from many plots in the same fields and in adjacent fields at the same time as the values lower than $0.9 \mathrm{r}^{2}$ were observed. The failures of the experiments occurred often at times when high fluxes were being observed in the fields, as will be discussed later. In general, however, if the concentrations in the chamber are small and comparable to background levels, the $\mathrm{r}^{2}$ is below the criterion value for all plots sampled at the same time, and the maximum concentration changes in the chamber are also small, then low $r^{2}$ values aré most likely due to lack of flux rather than to failed experiments. Such was the case for many of our zero-plant plot experiments, to be discussed later.

We conducted a careful analysis of the failed experiments to understand the nature of the problems encountered so that we could improve the sampling procedures. Several classes of accumulation profiles were isolated. The possible causes of the failed experiments, in order of importance, appear to be (1) disturbance of the plants and soils, (2) poor mixing in the chambers, (3) saturation of instrument response, (4) clogging of the needle, and (5) experimenter errors.

In spite of our best efforts, it became apparent that the disturbance of the plants and hence the soil was a significant cause of failed experiments. When the initial concentration in the chamber was very high, and subsequent accumulation was variable, we concluded it was due to an initial disturbance of the soil when the chamber was installed. This occurred more frequently towards the end of the growing season. When the rice plants were fully grown, and when there were four plants in the chamber, it was difficult to get the plants into the chamber. Placing the chamber gently over the plants was not possible, as the plants had to be gathered together and crowded into the chamber. When there were fewer plants inside the base, this problem was not as severe. Hence a high percentage of experiments with four plants in the chamber failed towards the end of the growing season.

Poor mixing in the chambers could have contributed to some of the anomalous profiles we observed. In such cases, although the concentrations in the chamber are high, there is no systematic accumulation; or there is one high concentration in the sequence of the four measurements that disturbs the linearity of the 
Table 4. Data Quality Assurance Statistics

\begin{tabular}{|c|c|c|c|c|c|c|c|c|c|c|}
\hline \multirow[b]{2}{*}{ Year } & \multicolumn{7}{|c|}{ Plots With Plants } & \multicolumn{3}{|c|}{ Zero Plant Plots } \\
\hline & All & $>0.9$ & $>0.95$ & $>0.99$ & $\begin{array}{l}\text { Back- } \\
\text { ground }\end{array}$ & Accepted & \%Accepted & All & $>0.9$ & $\%>0.99$ \\
\hline 1988 & 1653 & 1411 & 1249 & 818 & 228 & 1183 & 72 & & & \\
\hline 1989 & 1614 & 1310 & 1126 & 655 & 262 & 1048 & 65 & & & \\
\hline 1990 & 1032 & 853 & 751 & 429 & 169 & 684 & 66 & & & \\
\hline 1991 & 284 & 239 & 221 & 168 & 70 & 169 & 60 & & & \\
\hline 1992 & 702 & 419 & 333 & 153 & 60 & 359 & 51 & 214 & 36 & 17 \\
\hline 1993 & 826 & 556 & 475 & 269 & 40 & 516 & 62 & 413 & 132 & 32 \\
\hline $1994 \mathrm{~S}$ & 859 & 647 & 555 & 334 & 35 & 612 & 71 & 200 & 61 & 31 \\
\hline $1994 \mathrm{~L}$ & 153 & 139 & 126 & 99 & 2 & 137 & 90 & & & \\
\hline Total & 7123 & 5574 & 4836 & 2925 & 866 & 4708 & $66^{*}$ & 827 & 229 & $28^{*}$ \\
\hline
\end{tabular}

For 1994, $S$ stands for small chambers and $L$ for large chambers.

Numbers of flux measurements of acceptable quality.

$*$ means \% Total Accepted $=($ Total Accepted/Total All $) \times 100 \% ; \%>0.99=$ number with $r^{2}>0.99$ divided by all measurements $\times 100 \%$.

response. Other anomalous profiles could also be explained by poor mixing conditions.

In some cases, the concentrations in the chambers were so high that the GC/FID instrument did not accurately measure the high concentrations. Such cases are characterized by a "bending" of the accumulation curve with time. The rate of increase of methane in the chamber appears to slow down as the detector is saturated. Such profiles fail the linearity tests, or the background test, and are eliminated by these criteria. This is an effect of small chamber volume and is discussed further by Khalil et al., this issue (a).

Although we believe that most of the failed experiments were due to the disturbance of the plants and poor mixing, in some cases other problems were noted either from the field notes or upon an examination of the data. Partial clogging of the needle on the syringe creates a profile where one of the four values is very low, while the other three lie on a straight line, reducing the $r^{2}$ below 0.9 . In this case, as the needle is clogged, ambient air leaks into the syringe, causing low concentrations. We decided to eliminate data under such conditions, rather than recalculate the flux based on the three good measurements. Experimenter errors contributed to some failed experiments. In such cases the sequence of measurements was occasionally mislabeled or the time of the sample was not recorded accurately.

Based on these studies we retained only the data we consider to represent a correct flux measurement. Since we had taken a very large number of measurements, the elimination of failed experiments still leaves a large high quality database. The statistics of how much data passed the quality assurance criteria are listed in Table 4.

This table shows that, on average, about $1 / 3$ of the data did not pass the criteria; of this, most were eliminated by the correlation criteria, and the rest by the criterion related to the background concentration. Chambers with no plants tended to have very few cases when there is evidence of a flux (about $28 \%$ on the whole).

The small chambers created two problems specific to the size of the chambers. Taking flux measurements over very small areas captures fine spatial scale variability. While it is interesting to have a measure of this variability, it is a hinderance to the use of the data for estimating large scale emission rates representative of the fields. Second, the small chambers tend to get overcrowded with plants which can lead to disturbance of the soil during sampling, especially when the plants get big. This leads to invalid data, as has already been mentioned. Other factors such as poor mixing may also have played a role in many cases that had to be eliminated because of failure to satisfy the criteria. But regardless of these issues, there are inherent problems with the small chambers. We decided to discontinue their use and replace them with much larger chambers with fans for internal mixing. As shown in Table 4, some $90 \%$ of the experiments using the large chambers passed the criteria and in most cases with $r^{2}>0.95$. Whether installing fans in the small chambers would have significantly reduced the percent of data that had to be eliminated, cannot be determined from the current data set. The relationship between emissions based on the large chambers and small chambers requires some more explanation that has a bearing on the quality of the final data set, which will be discussed in the next section.

\subsection{Temperature Changes}

Our data show that changes of soil temperature significantly affect methane emission rates. When chambers are placed on the rice fields, the soil and air temperatures inside increase during the 12-15 min of the experiments. While we do not think that this length of time is sufficient to cause increases of methane production, we wanted to be certain that the plants were not under stress, which might cause feedbacks that could affect the transport efficiency of methane through the plants. We took measurements of inside and outside temperatures to determine the heating effect during the sampling period. This was done systematically in 1994 and occasionally in other years. There was not much difference of the temperature changes inside the small and large chambers. There were 2040 temperature measurements from small chamber plots and 306 from the large chambers. These data show that $99 \%$ of the differences in temperature inside the chambers at the end of the $15-20 \mathrm{~min}$ experiment, compared to outside the chambers are within $\pm 3^{\circ} \mathrm{C}$, for both small and large chambers and soil and air temperatures. The soil temperatures within the large chambers were most stable, with $92 \%$ of the measurements falling within $\pm 1^{\circ} \mathrm{C}$, which we take to mean that no change of soil temperature is observed for the large chambers. For small chambers $87 \%$ of the observations were within $\pm 1^{\circ} \mathrm{C}$ for the soil temperature. The increase of air temperature was larger, with a maximum observation of $6^{\circ} \mathrm{C}$. These maximum temperature changes occur over a relatively short time and are not 
expected to affect methane emissions during sampling. We found that temperature increases were unavoidable and occurred even when the chamber was insulated and covered with reflective foil. We believe that the chamber causes a greenhouse effect by preventing natural convection.

\section{Effect of Planting Density and Data Validation}

\subsection{Planting Density}

The base of the small chambers was of such a size as to allow the planting of no plants to four plants without having too sparse or too crowded a planting compared to the normal planting density in the fields. This happened because the side of the base was approximately of the same length as the distance between rice plants in the field. So one plant in the middle of the base or four plants, one in each comer, were both close to the apparent planting densities in the field. But when there were four plants in the chamber, the effective sampling density was about four times that of the field. This is because not only are there four plants in the chamber, but the aluminum base is embedded into the soil as discussed earlier. The base effectively confines the tillers to within the basal boundary. With four plants, although they start out with a planting distance just a little less than the rest of the field, because of the confinement by the base, the tillers spread toward the center rather than in all directions. The roots also are expected to follow this path, thus effectively confining the plants roughly to the basal dimensions. Moreover, because of the collar below the soil, the early roots, which have a tendency to spread laterally, are restricted from expanding beyond the basal boundary [see Grist, 1986). In the end, the effect of the base is to reflect a higher than field planting density if more than one plant is put into the base, and certainly for the case of the four plants in the base. Because the plants are not strictly cut off from the field, the four plants in a plot may not be exactly the same as four times as many plants in the entire field, but we believe that our experimments are a surrogate for such a case. To our knowledge there are no reports of the effect of planting density on methane emissions, in the laboratory or in the field. But, as is evident from our results, planting density has an important influence on methane emissions and on the field measurements if small chambers are used.

The farmers often chose to plant four plants inside the base of our chambers, one near each corner. In the first year, 1988, the number of plants in the chamber was not recorded but was reconstructed from numerous photographs taken during the course of setting up and starting the experiment.

The reconstruction was done when it became apparent that planting density inside the chambers affects the measured fluxes. In 1989, the number of plants in each chamber was recorded and varied between two and four; in 1990, most chambers had four plants, but there were three plots with fewer plants. The analysis of the 1989 and 1990 data suggested that the number of plants inside the chamber affected methane emission rates: more plants, more emissions. We had not known of this effect when we published the results of the first 2 years, where we overestimated the emission rates representative of the field because of larger than normal planting density inside the chambers [Khalil et al., 1991]. This effect was found too late to influence the 1991 experiments in which all chambers had four plants; for the 1992 experiments, we designed a sampling strategy to systematically measure the effect of planting density so that past data could be corrected. Chambers had 0 plants, one plant, or four plants. The results from 1992 suggested a complex relationship between planting density and methane emissions. Four plants did not produce four times the emissions from the one plant cases. The effect of planting density varied systematically during the growing season. We decided to repeat the experiments with more plots in 1993 with the idea for deriving a factor that would allow us to correct all the experiments to the emissions that would have been measured if the density of rice plants inside the chambers was equal to the prevailing planting density in the rice fields.

It turned out that the prevailing planting densities are remarkably similar among all fields, over all years, and even in different parts of the world where we have taken such measurements. We found that the average distance between the plants was about $21 \mathrm{~cm}$ in the fields we studied. One plant inside the area of our base was within $10 \%$ of the planting density of the fields we studied. The one plant plot became our standard for the emissions from the rice field representative of the prevailing planting density. Our subsequent experiments, such as in Indonesia, had one plant per chamber, and the prevailing planting density was verified to be represented by this case [Husin et al., 1995].

If large chambers are used, the number of plants inside the base represent the prevailing planting density regardless of how the chamber is placed. A widely varying number of plants cannot be placed inside large chambers and still maintain the density inside close to the prevailing field plant density. If the small chambers, with one plant, are good representatives of the field planting densities, then fluxes measured from such chambers should agree with fluxes measured from the large chambers (which represent the effect of the prevailing planting density in the field). We designed new experiments in 1993 and implemented them in 1994 using large and small chambers. These experiments were to be repeated in 1995 , but no usable data were obtained in this year due to a failure of the analytical instrumentation. After the 1995 growing season, we closed our experiments at $\mathrm{Tu} \mathrm{Zu}$.

The sequence of experiments described here explains the systematic process of determining the methane emissions representative of the fields we have studied and the time it took to obtain sufficient information to produce the final data set that correctly represents the emissions from the rice fields with the prevailing planting density.

\subsection{Corrections for Planting Density}

The effect of planting density is shown in Figure 2 in a characteristic example from the experiments in 1994. It shows the ratio of the emissions from four-plant plots to one-plant plots. The general features are that there is a small difference in the beginning of the growing season and toward the end of the growing season. In between, the four-plant plots emit significantly more methane than the one plant plots. The relationship between planting density and emissions is non-linear both in time during the growing season and with the number of plants. This pattern can be explained by considering the processes that control methane emissions from rice fields, and will be discussed in a companion paper [Khalil et al., this issue (c)]. For each year a correction factor is determined for each day of the growing season using the available data on emission from plots with different numbers of plants.

A practical method is to expand the flux as a function of planting density $N$ in a Taylor series around $N_{f}$ (the prevailing field planting density). We choose to do this expansion in the natural logarithm of the number density and flux so that we can 


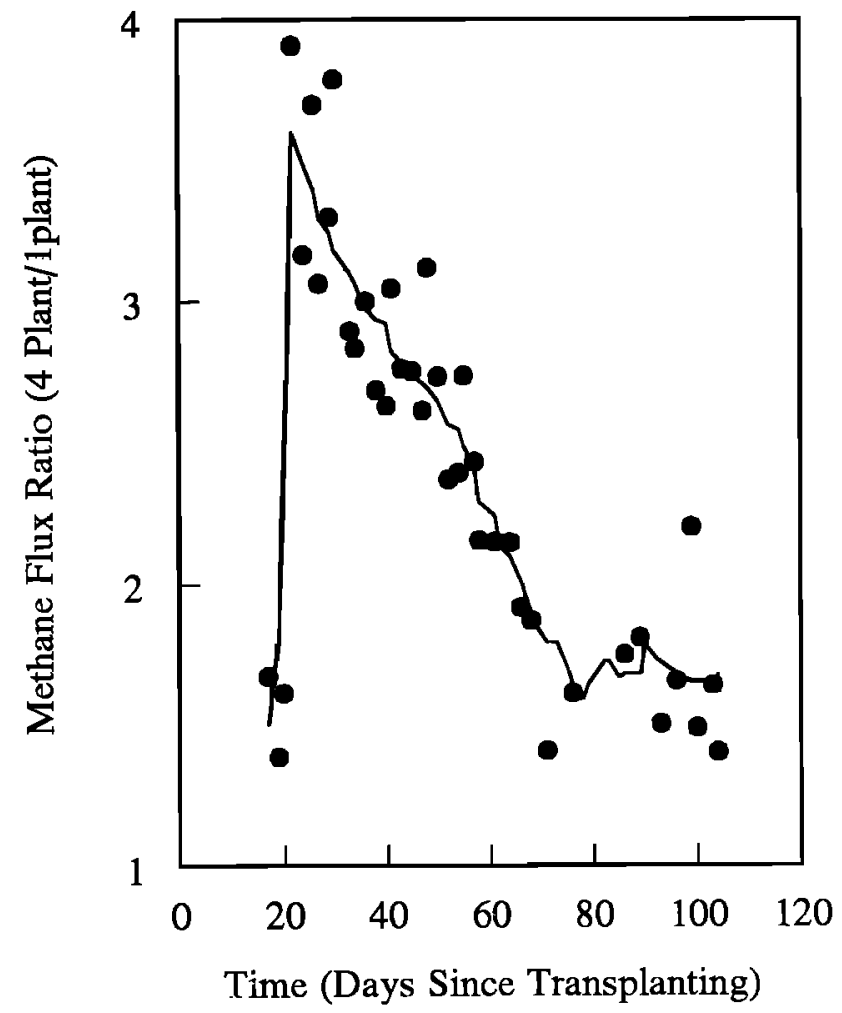

Figure 2. The ratio of measured average fluxes from all plots with four plants to plots with one plant (for 1994). The fourplant plots produced about twice as much methane as the oneplant plots during the growing season. This pattern may be explained by transport limited emissions in the earlier stages as the plants take root. In this period, more plants lead to more emissions as the transport pathways are the rate-limiting step. After tillering, there are numerous plant-mediated transport pathways, and the emissions become production-limited, with more plants not necessarily leading to more emissions. Other changes in the production, oxidation, and aging of the plants may also be significant in explaining this pattern.

deal with ratios rather than differences. The following results are obtained:

$$
\begin{gathered}
F\left(N_{f}, t\right)=\left[N_{f} / M\right]^{g(t)} \times F(M, t) \\
g(t)=\ln \left[F\left(N_{a}, t\right) / F\left(N_{b}, t\right)\right] / \ln \left[N_{a} / N_{b}\right]
\end{gathered}
$$

where $N_{a}$ and $N_{b}$ are the planting densities at which the fluxes $F\left(N_{a}, t\right)$ and $F\left(N_{b}, t\right)$ were measured and $M$ is the planting density inside the chamber at which measurements were taken. It should be noted that $g$ is a function of time during the growing season for the reasons mentioned earlier.

This is an empirical interpolation-extrapolation method for obtaining the emission rates at the prevailing planting densities of the rice fields when measurements were taken at densities different from the prevailing density. It provides no information on the mechanisms or the reasons why the flux should be different for different planting densities.

The observed relationship of flux with planting density was similar from year to year. During the growing season, on average, the four-plant plots emit about twice as much methane as the one-plant plots. The data for plots with more than one plant are multiplied by this factor to obtain the equivalent emissions for one plant per plot, which we determined to be the prevailing planting density of the fields. In 1991 there were only four-plant plots, so a composite correction factor from other years had to be applied. Here, and elsewhere, we use only the data corrected to the one plant per plot equivalent based on the relationships derived from our systematic experiments.

\subsection{Data Validation}

We conducted experiments with large chambers to see if the small chambers can represent the emissions from the field and not just the small scale fluxes, which may not be the same as the emissions from the field as a whole (see description of chambers in section 2.2.2). We installed small chambers inside the boundaries of the large chambers as well as outside the large chambers. If the small chambers with one plant represent the emissions from the field, then fluxes measured using small chambers should agree with the measurements from the large chambers, because the large chambers represent the planting density of the field. These experiments were designed to validate the data from all previous years or show if there are significant artifacts from the use of small chambers.

In each of fields 1,3 , and 4 we used a large chamber with three small chambers inside the large chambers and three small chambers outside. This gives us three replicates for large chambers (in different fields), with three replicates in each field of the small chambers inside and outside the large chambers for each field. The results show a close relationship between the fluxes measured by the small chambers inside the big chambers with the fluxes measured from the big chambers and also a good relationship between the small chambers placed outside the big chambers in the same fields. The quantitative relationships between the measurements from small and large chambers are calculated using the correlation coefficient, $r$, and the linear relationship between the measurements from the two types of chambers. The linear relationship is Flux (small chamber) $=b \times$ Flux (large chamber). If the relationship is good, " $r$ " and " $b$ " should be near 1 . This is indeed the case, as we will show next.

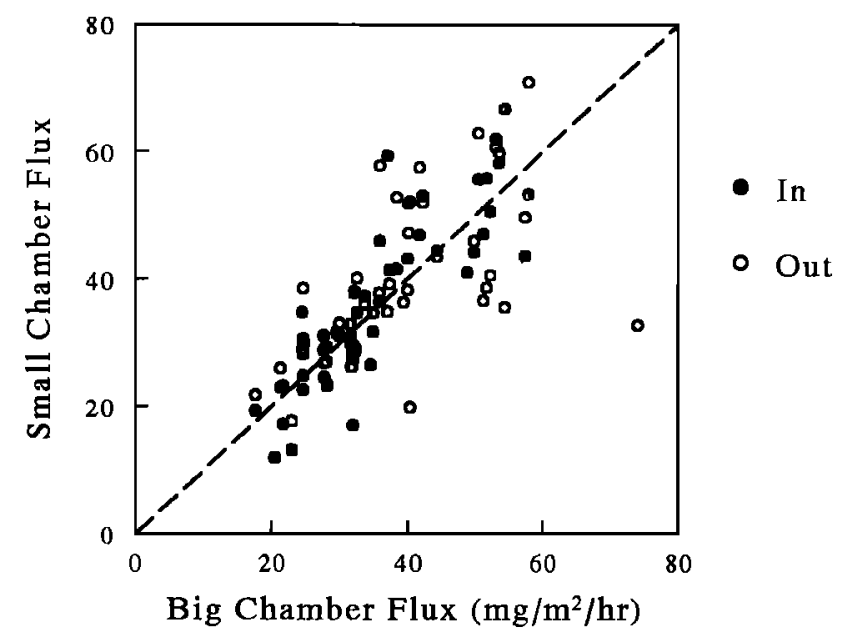

Figure 3. The relationship between fluxes measured using small chambers and large chambers. Some small chambers were inside the large chambers (solid circles marked "in"); others were outside the large chambers (open circles marked "out"). The correlation for all small chamber flux measurements compared to large chamber measurements is $\mathbf{0 . 8 7}$. 


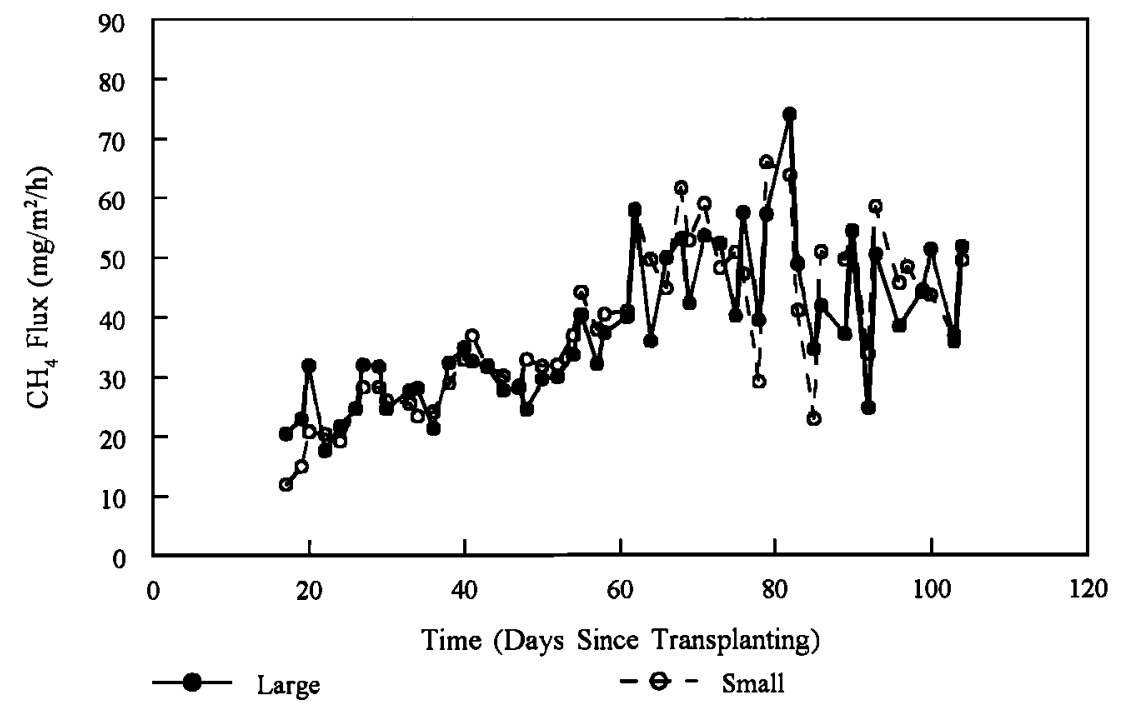

Figure 4. The seasonal cycle of methane fluxes measured using small and large chambers (for 1994). These results show the average of all small plot fluxes, both in and out of the large chambers, compared to the average of fluxes measured with the large chambers. The composite of all fields, as shown here, is our best estimate for emissions of methane from rice fields for the season.

The composite (average) of all small plot fluxes and the composite of all large chamber fluxes has a correlation of 0.87 and a slope of $1.01 \pm 0.03$; the composite of all fluxes from small plots inside the big chambers, compared to the composite of all large chamber fluxes gives a correlation of 0.85 and a slope of $1.03 \pm 0.03$; and small chambers outside the large chambers compared to large chamber fluxes gives a correlation of 0.62 with a slope of $0.97 \pm 0.04$. The measured fluxes based on small and large chambers, at the same time, can be compared by taking an average of the differences. For each day when measurements were taken, a difference can be calculated. The average difference over the whole growing season is an indication of how well the fluxes based on small chambers agree with fluxes determined from the large chambers, and whether there are any systematic differences. For the composite data, the seasonally averaged difference by this method, between big and small chamber fluxes, is only $0.6 \pm 0.9 \mathrm{mg} / \mathrm{m}^{2} / \mathrm{h}$. These relationships are demonstrated in Figures 3 and 4.

We believe that these composite results validate the averaged data from the small chambers during the 7-year course of the experiment, after correction for planting density. We further investigated the relationships to establish the limits of variability introduced by the small chambers on the scales of each field. The results are shown in Figure 5. In these graphs the average flux from all small chambers in a field is shown in comparison to the results from the large chamber in the same field. At the level of each field, the relationship between fluxes from small and large chambers is not expected to be as dramatic as the composite of all fields discussed above, but we find it is still solid.

For each field, the quantitative measures for similarity of fluxes, namely $r$ and $b$, are shown in Figure 6. In these figures we plot the correlation and the slope (with the standard error), for three comparisons. The first set is the comparison of the flux from the large chamber, in a given field, with the average flux from the small chambers inside the big chamber (R3-IN, R4-IN, and R1-IN for fields 3, 4, and 1 respectively). Also included is the relationship between the average of all large chambers and the average of all small chambers inside the large chambers (Avg-In).
The next set of calculations is for the comparison between the average of all small chambers (inside and outside the large chamber) and the large chamber in each field ( $R x$-ALL, where $x$ is the field number), and the average of all small chambers and all large chambers (Avg-ALL). The last set of calculations is a comparison of the fluxes from the chambers outside the large chamber with the flux from the large chamber in each field $(R x$ OUT, where $x$ is the field number), and the composite of all small chambers outside the large chambers compared to the average of all large chambers (Avg-OUT).

As might be expected, the small chambers inside the large chambers agree best with the fluxes calculated from the large chamber. For this case, the slope is between 0.99 and 1.03 and is statistically indistinguishable from 1 at the $5 \%$ level or less. The correlation coefficients are $0.51,0.75$, and 0.82 for fields 1,4 , and 3. Except for the case of field 1, these correlations are quite high. When we compare the fluxes measured by using the small plots outside the big chambers, with the fluxes measured using the big chambers, the correlations and slopes drop (last group of points in Figure 6). The relatively low correlation between small and large plots for field $1(r=0.51)$ is an anomaly. An examination of the results for this case suggests that the low correlation is due to a few discrepancies in the later stages of the growing season, as can be seen in Figure 6a. If four pairs out of 41 pairs of observations are eliminated, the correlation coefficient is 0.72 . The figure also shows that in field 1 , the overall seasonal pattern of the emissions is well represented by the emissions calculated from the small plots when compared to the large plots. For this reason we believe that this somewhat low correlation does not affect the conclusion that the small plots, with one plant per plot, taken in aggregate, fully represent the emissions from the whole rice field, and introduce a relatively small uncertainty in the flux, which we discuss next.

The next set of comparisons evaluate the average difference of the flux between small and large chambers for the field average (Figure 7). This figure shows the comparisons of fluxes from large chambers with fluxes from small chambers inside the large chambers (dFLIn), small chambers outside the large chambers 

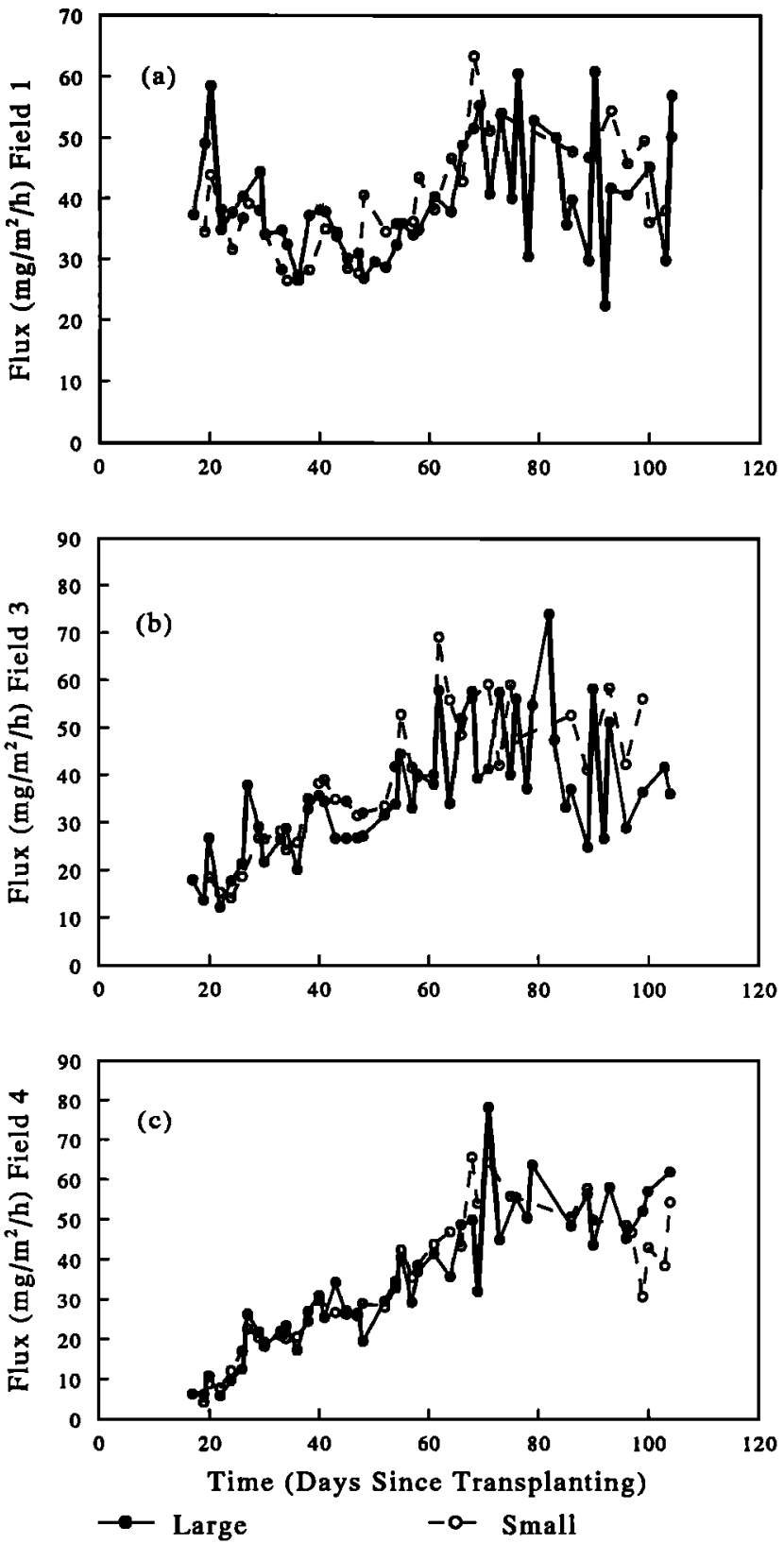

Figure 5. The seasonal cycle of methane fluxes measured in small and large chambers, for each of the three fields where this experiment was done (1994).

with the large chambers (dFLOut), small chambers inside with small chambers outside the large chambers (dFOutIn) and the comparison of all small chambers, inside and outside the big chambers, with the fluxes measured from the big chambers. The agreement between the small and large chambers is within \pm 2 $\mathrm{mg} / \mathrm{m}^{2} / \mathrm{h}$ for the small chamber inside the big chambers. Emissions estimated from chambers that were outside the large chambers, when compared to the large chambers, is somewhat less, and is worst for field 3 , where it is up to $8 \mathrm{mg} / \mathrm{m}^{2} / \mathrm{h}$. We believe that this difference is not related to chamber size but is due to spatial variability of flux in the field. This conclusion is based on the fact that the fluxes from the small chambers inside the big chamber agree. The difference between the average of all small chambers and all large chambers, in each field, is less than $5 \mathrm{mg} / \mathrm{m}^{2} / \mathrm{h}$, mostly affected by field 3 ; otherwise it would be less than $\pm 2 \mathrm{mg} / \mathrm{m}^{2} / \mathrm{hr}$. On the basis of these comparisons, we believe that small chambers may lead to an uncertainty of up to \pm 2 $\mathrm{mg} / \mathrm{m}^{2} / \mathrm{h}$ for the seasonal average emission rates, at the field level, assuming that the large chambers represent the field emission rates.

The two sets of numbers, $r$ and $b$, together establish that the small chambers do indeed represent the emissions from the rice fields with one plant per small plot. The small chambers faithfully represent the seasonal and diurnal variability of methane emissions from rice fields, and the seasonal average emission rate. On a field by field basis, the small and large
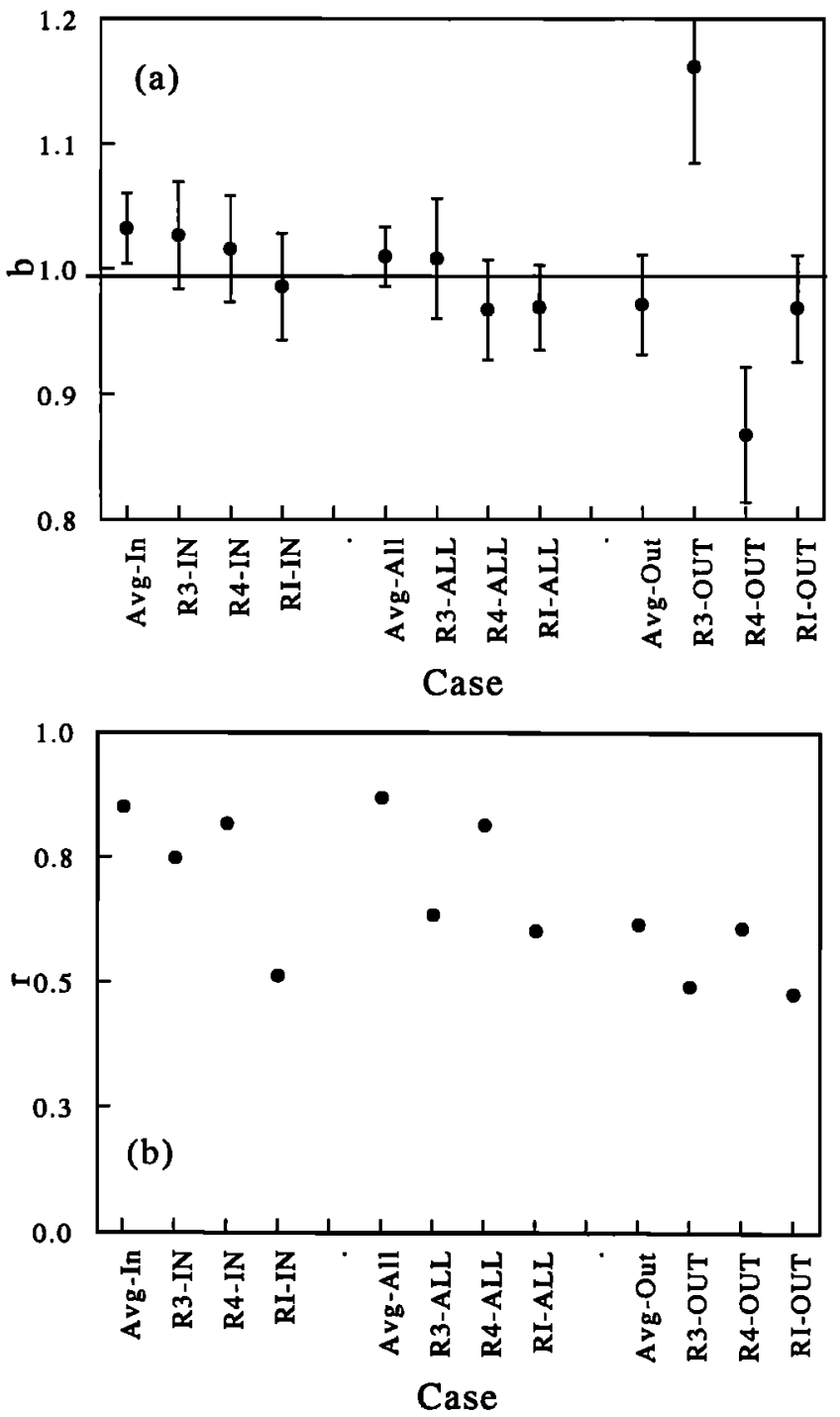

Figure 6. The agreement between fluxes measured with small and large chambers. The indices of agreement are $b$ and $r$, where $b$ is the slope of the regression line between the fluxes measured by the two types of chambers, and $\boldsymbol{r}$ is the correlation coefficient. Perfect agreement would require both indices to equal one (see text for further discussion). Avg refers to flux averaged over all fields; IN refers to the small chambers inside the large chambers; OUT refers to small chambers placed outside the large chambers (in the same field); ALL refers to all small chambers both inside and outside the large chambers, and R1, R3, R4 refer to each of three fields studied. The results show all possible different comparisons, both for each of the fields and for the composite of all three fields (Avg). Vertical bars are standard errors. 


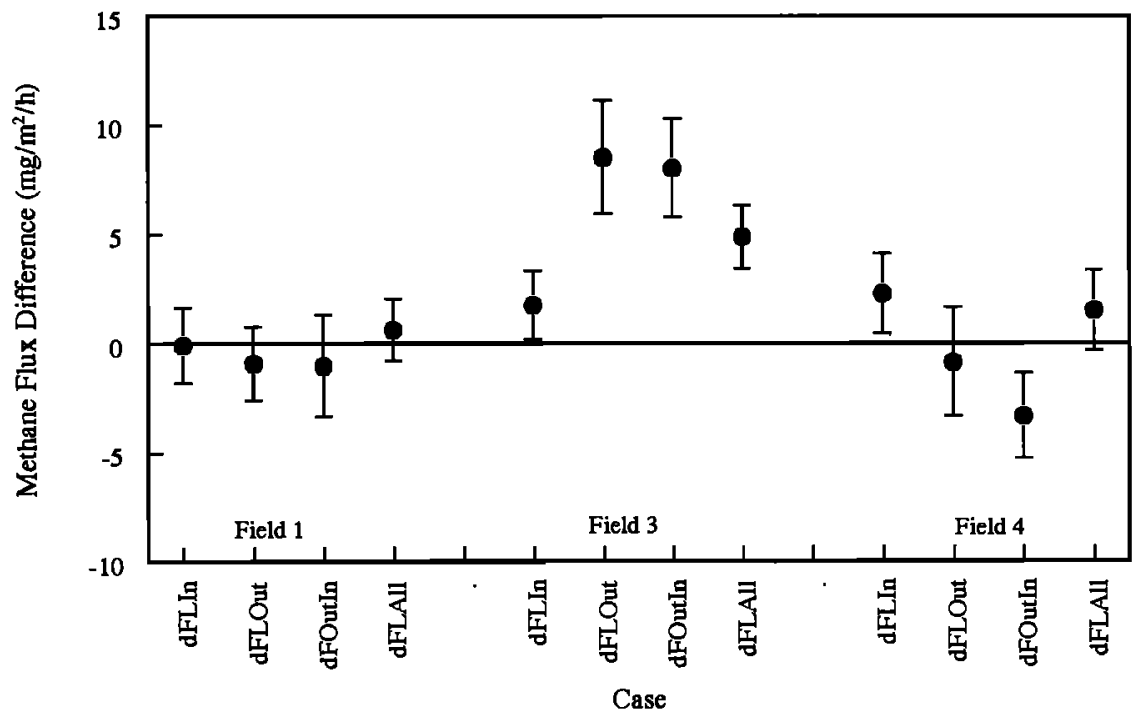

Figure 7. The seasonally averaged differences of fluxes measured using small and large chambers. The vertical bars are standard errors. The symbols on the abscissa are $d F x y$ where $d F$ is for difference of flux; $x=L$ for large chambers; OUT for small chambers outside the large chambers; or ALL for small chambers both inside and outside the large chambers; $y=$ In, Out, or All where In refers to small chambers inside the large chambers. Results are shown for each of the three fields studied in this experiment.

chambers have modest differences that are unlikely to affect most of the conclusions drawn from the data. When all plots are averaged to obtain a single flux from the fields for each day, the results from small chambers and large chambers are practically indistinguishable. Further analyses of the data also provide evidence of consistency and validity [Khalil et al., this issue, a, b].

To further validate the flux measurements reported here, we have used ambient concentrations to independently estimate methane emissions. The method is to use date from the base year (1988) to determine the relationship between emissions and ambient concentrations taking into account the factors that affect the dispersion of methane from an area-wide source. This semiempirical relationship is applied to the measured ambient concentrations in subsequent years (1989-1994) to estimate the methane flux. The method only allows us to compare the seasonal pattem of emissions and the seasonal average flux, with the actual measurements of these patterns. On both these measures, this independent calculation agrees well with the direct flux measurements. Using the composite data from all years the root-mean-square deviation representing the seasonal pattern, relative to seasonally averaged flux, is $\pm 10 \%$, and the difference of the seasonally averaged emission rate is less than $3 \%$ between direct measurements and flux estimates based on ambient concentrations [Khalil and Rasmussen, 1990, 1998].

\section{Results}

\subsection{Final Data Set}

The data from all years have certain features in common, which are also seen in other published data. The emissions of methane are small when rice is planted, being a few $\mathrm{mg} / \mathrm{m}^{2} / \mathrm{h}$. Emissions increase as the rice plants grow and reach a peak value, up to $100 \mathrm{mg} / \mathrm{m}^{2} / \mathrm{h}$ around the time of flowering. After this time emissions drop slowly until harvest time when emissions are around $10 \mathrm{mg} / \mathrm{m}^{2} / \mathrm{h}$. Superimposed on this general pattern is the within-season variability. The increases and decreases of methane emissions during the growing season are caused by several processes, the most important of which may be soil temperature variations. Other factors such as fertilizer application, and more complex below-ground processes may also be significant in explaining these variations of emissions during the growing season. Some of these factors will be discussed in another paper [Khalil et al., this issue, b]

We define some variables to describe the data and their analysis. As stated earlier, we obtained data from up to 24 plots in four fields close to each other, over the seven-year period between 1988 and 1994 . We therefore have a time series of flux measurements during the growing season from each plot which we can write as $\phi[p, f, T(t, d), y]$ where $p$ is the plot number $(1, \ldots$, $6), f$ is the field number $(1, \ldots, 4), t$ is the time of day, $d$ is the days since transplanting $(0, \ldots, 130)$ or the calendar date (dates in March, ..., September) ending at harvest, and $y$ is the year of the measurement $(1988, \ldots, 1994) . T(l, d)$ is used to combine the time of day and the days since transplanting into one variable as more than one set of measurements was not taken on the same day. Each datum can be uniquely identified by these five indices. As mentioned earlier, there are many gaps in the data at the plot level after application of the quality control criteria, especially towards the end of the growing season. For this and other reasons, we believe that the data are most useful if viewed either at the "field level" or the "area level."

The field level is the average flux for each field or $\Phi[f, T(t, d), y]$ and the area level is the average flux for the entire area sampled which includes all four fields. Since we did not find major differences of emissions between the fields, we calculated the area average as the average of all plots (up to 24) in the four fields and the standard deviation of the data as a measure of variability, designated $\langle\phi[T(t, d), y]\rangle$ for the average. For most uses, the area averages will be sufficient, so these are included in Table 1. In addition to these data sets for methane emissions, we can also define $\phi(p, f, d)$ where the year of the measurement and the time of day are suppressed. This creates a seasonal composite of all years of measurements. The time of day $t$ is not important 


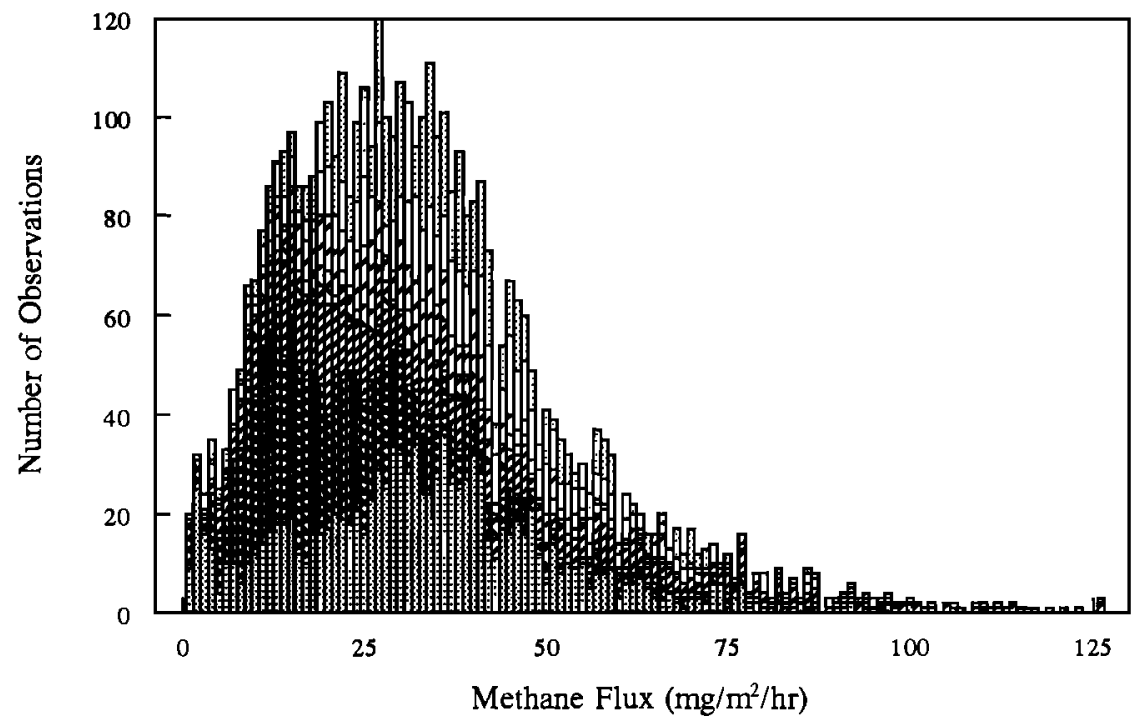

Figure 8. The frequency distribution of methane fluxes from 1988 to 1994 at $\mathrm{Tu} \mathrm{Zu}$, China. Data from each year are represented by a different cross-hatch mark. The 1988 data are at the bottom. Nearly 5000 flux measurements are included in this figure. The median emissions are $30 \mathrm{mg} / \mathrm{m}^{2} / \mathrm{h}$. The figure includes systematic seasonal variability and is not an indicator of the random variability of measured fluxes.

in this composite data set since the interannual variability overshadows the relatively small diurnal variability (the diumal variability will be considered later in this paper). Again, these data can be averaged over the field, $\Phi(f, d)$, and over the entire area, $\langle\phi(d)\rangle$.

5.1.1. Plots with plants. The main results of the work are shown in a series of figures that describe the nature of the data set. These figures show the frequency distribution of the data, the seasonal cycle of emissions, the seven-year time series of the measurements, and the emissions during each year of measurement.

Figure 8 shows the frequency distribution of the nearly 5000 valid flux measurements during the years of the experiment. The figure cannot be easily interpreted in statistical terms since the individual data points are not random variations from some mean value but include systematic seasonal variability and variability caused by other environmental factors. Nonetheless, the figure gives an idea of the average, or most frequently measured flux rates, during the 7 years of the experiment and the overall variabılity that was observed. It is clear that the distribution is skewed towards the high side, with the most frequently observed emissions around $30 \mathrm{mg} / \mathrm{m}^{2} / \mathrm{h}$, which is also close to the seasonally averaged emission rate. The lower limit is near zero (and constrained by the detection limit of the experimental system). Valid fluxes over $100 \mathrm{mg} / \mathrm{m}^{2} / \mathrm{h}$ were rarely observed.

Figure 9 shows a composite emission rate from all the years of

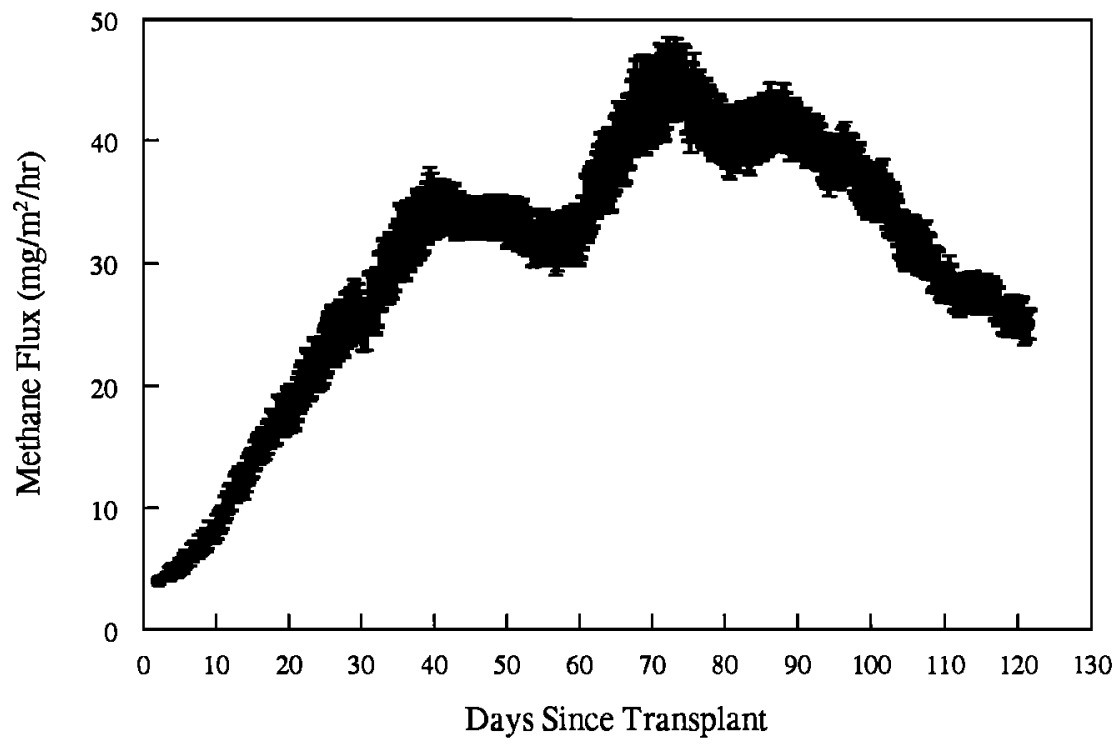

Figure 9. The average seasonal cycle of methane emissions from rice fields at Tu $\mathrm{Zu}$, China (1988-1994). This figure represents all years of data normalized to "days since transplanting." The results are smoothed by taking 30point running averages of both the emissions and the days since transplanting. The error bars, vertical and horizontal, are the standard errors for each 30-point average. 


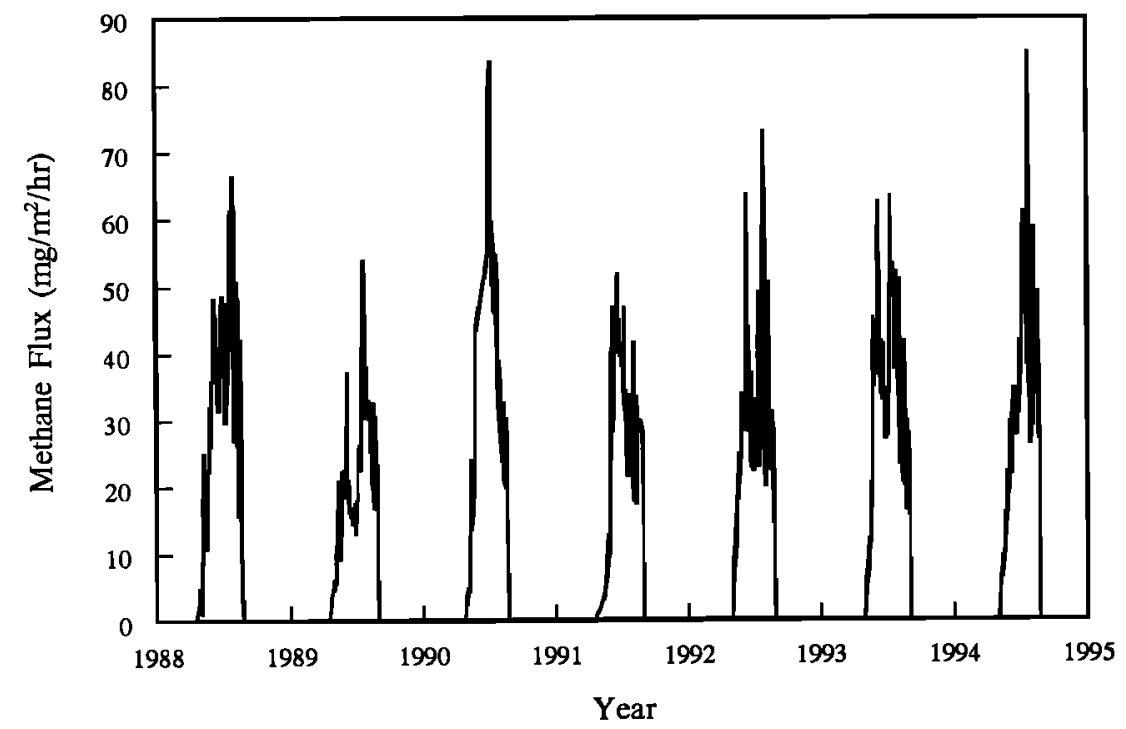

Figure 10. The time series of methane emissions from rice fields at $\mathrm{Tu} \mathrm{Zu}$, China, from 1988-1994. Possible emissions or uptake of methane after harvest is not shown.

data. It is constructed by taking the area averaged emissions from each year, as a function of days since transplanting, and combining the data from all years $\langle\phi(d)\rangle$. Then, a 30-point running average of the emissions is calculated along with the standard error of the mean emission rate (the vertical error bars). A 30-point running average of the days since transplanting is also calculated along with its standard error (horizontal bars). The average flux for each 30 data point "window" is placed at the 30 point average of the days since transplanting. We believe Figure 9 is an average representation of the seasonal cycle at our location and other regions represented by our data. It can be used for assessing the effects of seasonal variations of emissions from rice fields on the budget of methane. Figure 9 can be reconstructed from the data in Table 1 .

The time series of the daily average emission rates between 1988 and 1994, are shown in Figure 10: $\langle\phi(t, d, y)\rangle$ (data in Table 1). In making this graph, we have assumed that emissions between harvest and replanting next year are zero since no actual measurements were taken except during the growing season. This assumption is based on data obtained during one of the years which showed a modest methane uptake in the fields a week or so after harvest when the field was moist but had no standing water. Our fields were used for only a single rice crop per year, sometimes preceded by (canola) oil seed but fallow following the rice crop; in most cases there would be no standing water in the fields when rice is not present. There are conditions under which fallow rice fields will produce methane. The factors controlling such emissions are complex making it difficult to estimate their effect on the global scale. It should be noted that our data here and Figure 10 do not address the matter of fallow field methane emissions.

The data shown in the summary Figure 10 are expanded to show the results for each year, in Figures $11 \mathrm{a}-11 \mathrm{~g}\langle\phi(t, d, y)\rangle$. In these figures, we show the average emission rates for the days on which measurements were taken, and the standard error of estimated average. The average is formed from fluxes calculated at each plot, so up to 24 individual measurements make up a single day's average. The data used have been corrected for planting density and satisfy the quality control criteria discussed earlier. The actual number of data for each average is generally less than 24 , because some data are not valid as discussed earlier, and in some years, measurements were not taken at all 24 plots (see Table 2).

5.1.2. Plots without plants. In 1992, 1993, and 1994 we measured emissions from plots with no plants inside. As mentioned earlier, this can be done with small chambers without significantly affecting the planting density surrounding these plots. Since methane is emitted mostly through the plants, plots without plants were expected to show significantly lower fluxes. This is indeed the case and it put some limits on how much methane is emitted through the soil and water compared to the emissions through the plants.

The results, in Figure 12, show the seasonally averaged emissions from each plot with no plants. The average emissions from all plots (area level average) is $5 \pm 1,7 \pm 2$, and $8 \pm 2$ $\mathrm{mg} / \mathrm{m}^{2} / \mathrm{h}$ for 1992,1993 , and 1994 respectively. The average is about $6 \mathrm{mg} / \mathrm{m}^{2} / \mathrm{h}$ out of total emissions of a little over 30 $\mathrm{mg} / \mathrm{m}^{2} / \mathrm{h}$, or about $20 \%$. So for the whole growing season, $80 \%$ or so of the methane flux is from the plants.

The temporal nature of the emissions from the plots with no plants is quite unlike the patterns seen when plants are present in the chambers. We found that most of the time the flux from the plots with no plants was not measurable, but occasionally there would be sizable emissions. It is the collection of these times when emissions took place that contribute to the average emission rates calculated for the season. This finding is consistent with the idea that emissions from the soils, without plants, often take place by ebullition, which is a sporadic process. When the flux was not measurable it was not because the concentration of methane in the chambers was small, but rather that there was no systematic accumulation of methane in the chambers so that the regression of concentration in the chamber and time of sampling resulted in negative or positive values with very small correlation coefficients, well below the criteria discussed earlier. Because the plots with no plants were surrounded by the rice growing in the fields, the methane concentration in the air at these plots was quite high. These measurements give us an estimate of methane concentrations in rice fields below the tops of the plants. This information may be useful in establishing the transport efficiency of methane from within the field to the atmosphere above. The 

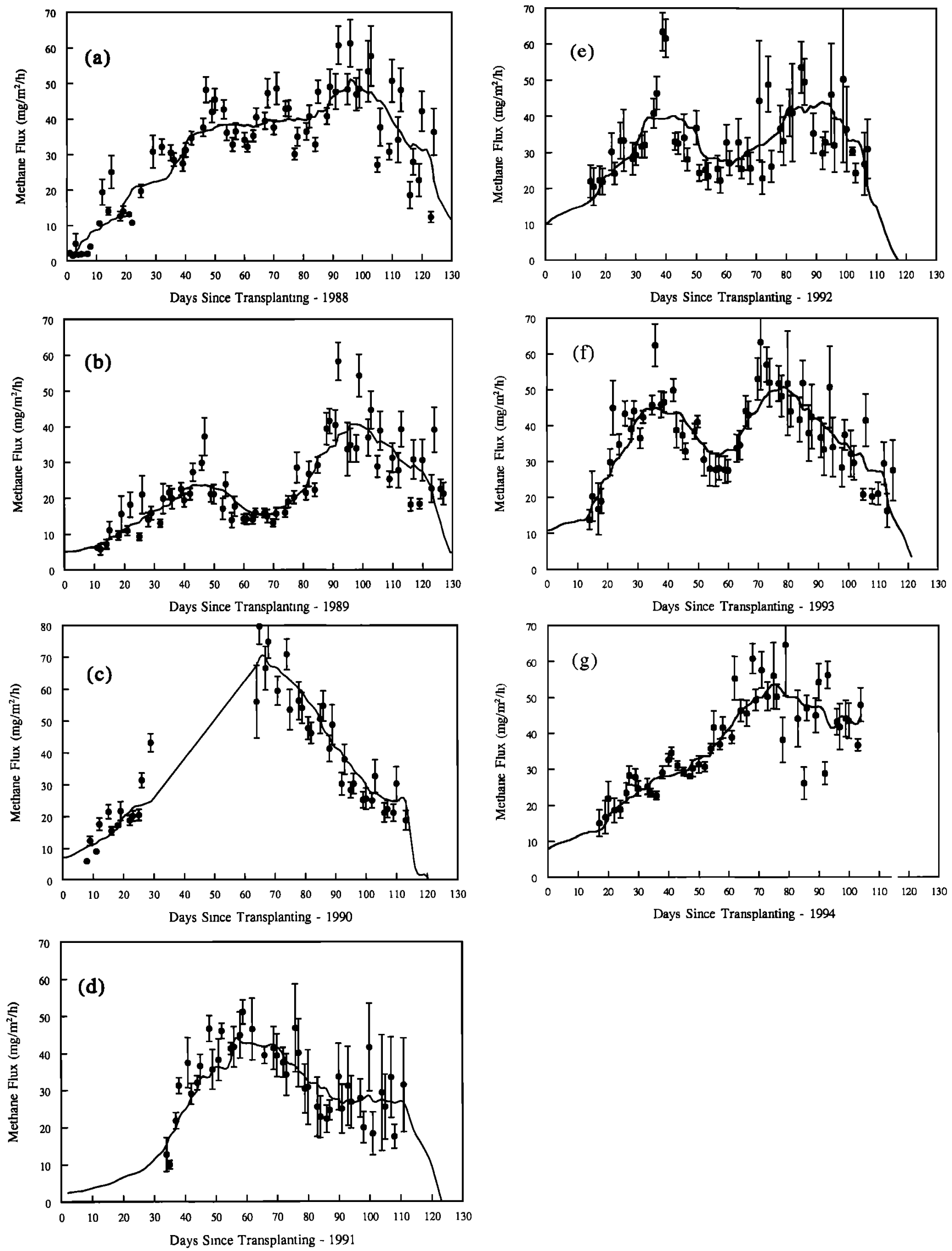

Figure 11. The time series of methane emissions from rice fields at $\mathrm{Tu} \mathrm{Zu}$, China, for the entire growing season during each year between 1988 and 1994 . The vertical bars are standard errors of the mean emission rate on the day when measurements were taken. This figure shows an expanded view of each year shown in Figure 10. 


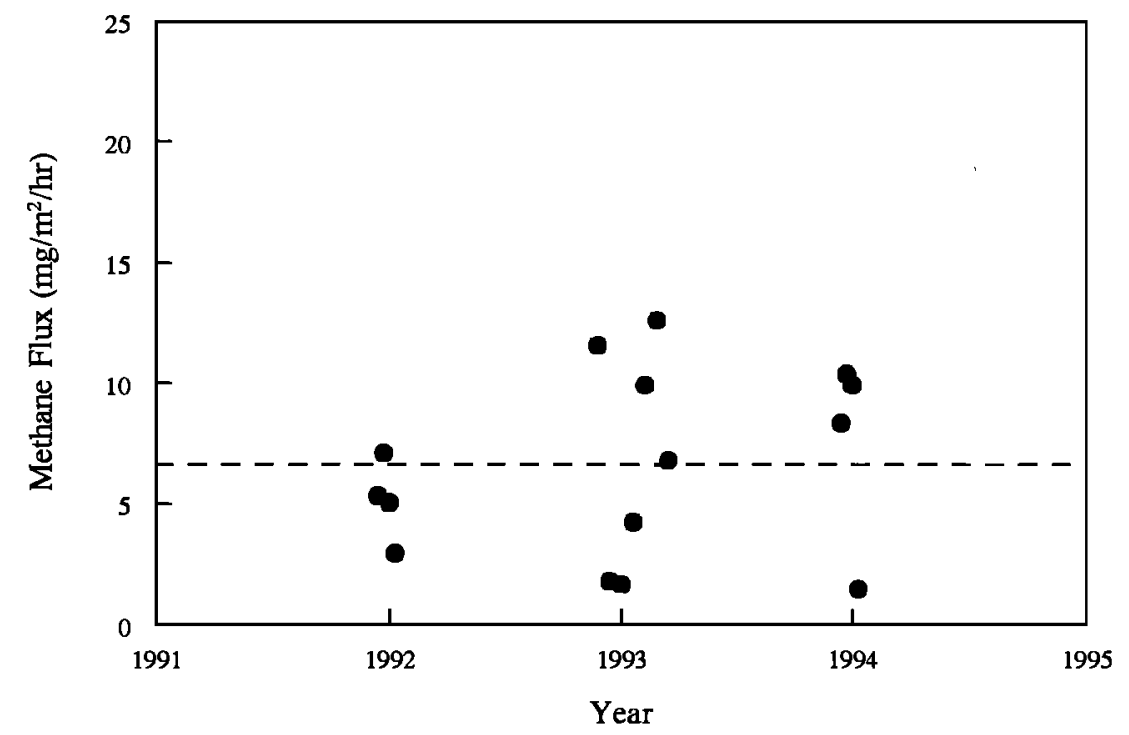

Figure 12. Methane emissions from plots with no plants. These represent the seasonal average emission rates. For most of the days when samples were collected, there were no emissions. When emissions were observed, the fluxes were quite high. Based on these results, it appears that, during the growing season, plants are responsible for some $80 \%$ of the emissions, and the rest come from exchange processes between the soil, water, and air.

observed concentrations under the canopy were variable with seasonal averages of $9 \mathrm{ppmv}$ to $125 \mathrm{ppmv}$ of methane at the plots with no plants. No correlation was observed with ambient concentrations near the fields, where the seasonal average concentrations are 3-5 ppmv.

\subsection{Annual Average Emission Rates}

While the seasonal emissions, as described in previous sections, are valuable for understanding the role of rice fields in the methane cycle, the seasonally averaged emission rates are equally important, and more commonly used, in evaluating the long term changes in atmospheric methane. In the global budget of methane, the seasonal average emission rates are used to estimate the annual emissions of methane from the rice fields. Our data represent a very extensive investigation of the whole season emission rates and their spatial and inter-annual changes. The whole season methane emissions are calculated as follows:

$$
\begin{gathered}
\Phi(p, f, y)=\frac{1}{N} \int_{0}^{N} \phi[p, f, T(t, d), y] d T \\
\text { Plot Level } \\
\Phi(f, y)=\frac{1}{N} \int_{0}^{N} \Phi[f, T(t, d), y] d T \approx \frac{1}{N_{p}} \sum_{p=1}^{N_{p}} \Phi(p, f, y) \quad \text { Field Level } \\
<\Phi(y)>=\frac{1}{N} \int_{0}^{N}<\phi[T(t, d), y]>d T \approx \frac{1}{N_{p} N_{f}} \sum_{p=1}^{N_{p}} \sum_{f=1}^{N_{f}} \Phi(p, f, y) \\
\text { A rea Level }
\end{gathered}
$$

The index $T$ is days since transplanting and includes the effect of the time of day $t$. Time $x$ is taken as 0 when the rice is planted, and so $N$ is the number of days between transplanting and harvest. $N_{p}$ and $N_{f}$ are the number of plots or fields sampled in the year.
These integrals in (4) are estimated . $v$ the following approximation:

$$
\int \phi(x) d x \approx \sum_{i=1}^{N}\left[\phi\left(t_{i}\right)+\phi\left(t_{i+1}\right)\right] / 2 \Delta_{i}
$$

Here, on the right hand side, we take the average of fluxes on two adjacent sampling days and use that as the estimate of the flux for the time between those two sampling days. It is then multiplied by the time $\Delta_{i}=\left(t_{i+1}-t_{i}\right)$ that this estimate covers. $\Delta_{i}$ ranges from 1 day to 4 days under normal circumstances, and longer if the data are missing. The product then is the estimate of total emissions per square meter for the period covered by $\Delta_{t}$. This method gives a robust estimate and takes into account both the diurnal variability and interpolation of missing data. The rightmost approximations in (4) represent estimates of "field" and "area" level emissions based on averaging the seasonally averaged emissions from each plot.

The data we have shown in Figure 11 indicate that in most years there is a gap between the transplanting date and the start of the sampling. To get the whole season average flux we extrapolate the measurements back to the time of transplanting. For completeness, we do a similar extrapolation at the end of the sampling to go to the harvest date. This latter correction is only for a few days as samples were normally collected as close to harvest as possible.

The extrapolation of flux to the transplant date does not introduce any significant uncertainties in the integrated seasonal flux because emissions during this period are very low compared to later in the growing season, and therefore do not contribute greatly to the seasonal average. For consistency, we need a clear definition of the period of the whole season during which methane emissions occur; this we take to be between transplanting and harvest. We have taken these periods of missing data into account by using the first 2 years of data (1988 and 1989) when measurements were taken from transplanting day onward. We found that for the first month the flux can be approximated by $F_{0} \times e^{(-0.075 / \text { dey } \times r \text { days })}$ where $F_{0}$ is the average flux 

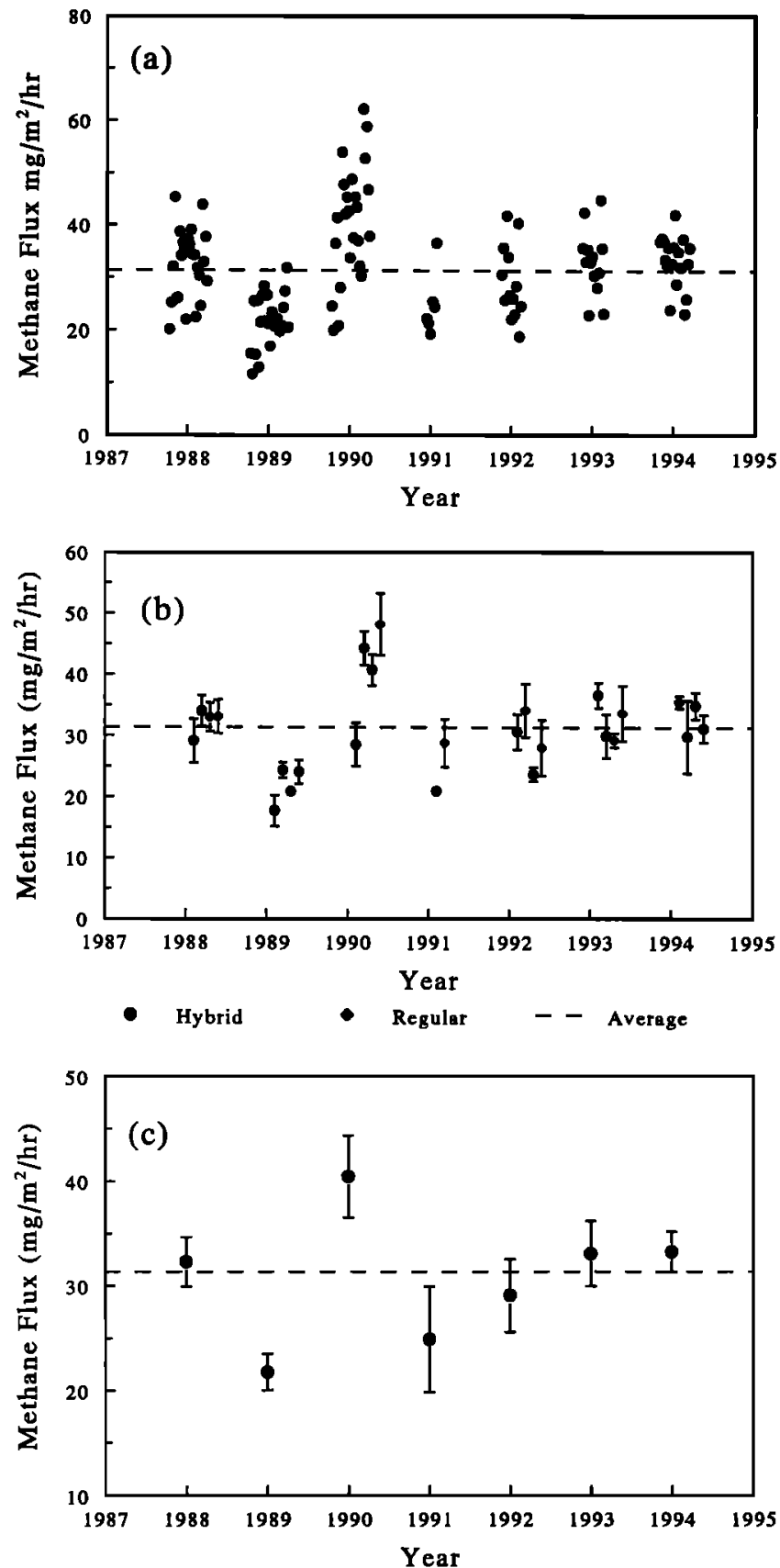

Figure 13. Average methane emissions from rice fields at $\mathrm{Tu} \mathrm{Zu}$, China. Data are for the whole growing season (100-120 days) from each plot, each field, and the whole area.

for the first week when measurements were taken. We have used this relationship for all later years to fill in the flux for the time between transplanting and the start of the measurements. The same exponential method is used to extrapolate to the harvest date but the estimated decrease of emissions for this period is $-0.02 / \mathrm{d}$.

During 1990 , as mentioned earlier, there was an instrument failure that resulted in a loss of data from 29 to 64 days after transplanting. The seasonal average was calculated by interpolating between the gap in the usual manner described above. To test the reliability of this calculation we constructed new data sets by taking out the data from the same number of days and during the same period (29 - 64 days after transplanting) from the measurements of the other years. We then calculated the seasonally averaged emission rates as for 1990 and compared the results to the calculations based on all the data. We found that taking out the data from days 29-64 causes maximum errors of $+28 \%$ and $-37 \%$ for the emissions from individual plots. In most cases the errors were within $\pm 20 \%$. At the field level, the error introduced by the missing data was between $+7 \%$ and $-10 \%$, and for the area-wide annual average emission rate, the error was only $+2 \%$ to $-4 \%$. Based on these results we are confident that the calculations, at least at the field and area levels, are reliable for 1990 even though we missed a month in the middle of the growing season.

The results are shown in Figures $13 \mathrm{a}-13 \mathrm{c}$ as seasonally averaged emission rates from each plot, each field, and all fields (area level). We calculated the seasonally averaged flux from each plot according to the methods discussed earlier. Since there are gaps in the plot level data, and the data tend to vary from plot to plot, there is considerable variability in the seasonal estimate of fluxes from each plot. This will be discussed quantitatively later. We then calculated the average and standard error of the estimate from each plot to construct the estimated seasonally averaged emission rate from each field (righthand side approximate in (4)). The other way to estimate this average is to take the field average first and then perform the integration as in (5). The results of the two methods are very similar, with small differences arising from the differences in the interpolation in the integration. The former method provides a more straightforward estimate of variability so it is included here. The area level estimates were also calculated by the several possible processes which all give nearly the same results. What is shown in Figure $13 \mathrm{c}$ is the average of all plots for each year and the standard error. From these results the total emissions for the season can be calculated by multiplying the average emissions reported in $\mathrm{mg} / \mathrm{m}^{2} / \mathrm{h}$ by the length of the growing season (hours) given in days in Table 2 for each year and field. The results (in $\mathrm{g} / \mathrm{m}^{2}$ ) are 1988: $97 \pm 4$; 1989: $66 \pm 4$; 1990: $113 \pm 14$; 1991: $71 \pm 9$; 1992: $78 \pm 7$; $1993: 93 \pm 4$; and 1994: $83 \pm 4$.

These figures show that the average emissions from rice fields in the area we studied are about $30 \mathrm{mg} / \mathrm{m}^{2} / \mathrm{hr}$ over the growing

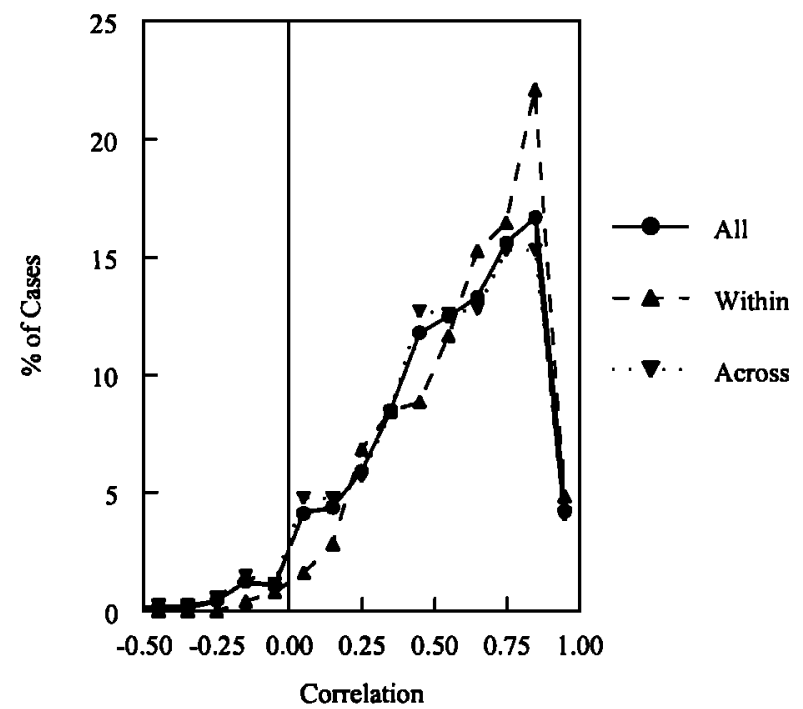

Figure 14. The distribution of correlations of methane emissions recorded at different plots. The results are for all 7 years of the experiment. The modal correlation is around 0.85 , while the mean correlation is around 0.65 . These results show that the plots have strong coherence. 
season. There are fluctuations from year to year and at different parts of the fields. Some of this variability is explained by the factors that control methane emissions from rice fields. Further analysis of the factors will be discussed in later papers [Khalil et $a l$. , this issue, b]. Here we want to document the extent of the variability and its implications for the present data set.

\subsection{Variability}

There are several different cycles and fluctuations embedded in the data set representing the temporal variability. The first is the systematic seasonal variability that has already been discussed in section 5.1. Another form of systematic variability is the diurnal cycle of methane emissions, to be discussed later. In addition to the seasonal and diumal cycles there are two other forms of variability that are of considerable interest. The first is the spatial variability within and among the fields, as this establishes how precisely we can measure large scale emission rates using chambers, which then has an effect on the uncertainties in the estimated larger scale or even global emission rates. The second is the interannual variability that has a bearing on the trends of methane as well as the robustness of an annual estimate. We will discuss the spatial, diurnal, and interannual variabilities to complete the description of the data and the quantifiable uncertainties.

5.3.1. Spatial variability and coherence. We considered the spatial variability of the temporal patterns by calculating the correlation coefficients, $r\left(p_{t}, p_{j} y\right)$, between plot $i$ and plot $j$ during the year $y$, when $i$ and $j$ are not the same. We take these correlations to measure the coherence of the plots or how well the plots agree on seasonal patterns. Similarly, we calculate $r\left(f_{i} f, y\right)$ for the correlation between the average emissions from fields $i$ and $j$. This measure is different from the spatial variability of absolute flux. Two plots, or fields, can have highly correlated fluxes but quite different absolute emission rates. For the plot level, we limited the calculations to cases when 10 or more pairs of measurements were available through the growing season; otherwise, the correlation coefficients were unreliable and greatly affected by one or two points.

Over the years of the experiments 1113 valid correlation coefficients were generated, with 249 for plots that were within the same fields and 865 for plots that were not in the same fields. The results are summarized in Figure 14, which shows the frequency distribution of the correlation coefficients, with data from all years pooled together. The modal value of the correlations is quite high at about 0.85 . The average correlations are smaller, however, at $\mathbf{0 . 6 5}$ for plots in the same field and 0.6 for the plots across fields (among fields). The pattern shown in the figure suggests strong correlations and hence strong coherence among the patterns observed with the various plots. These correlations are driven by the different cycles in the data. Much of the correlation occurs because all plots tend to reproduce the seasonal cycle of emission with peak emission rates during the middle of the growing season. Once this cycle is taken out, the correlations among the plots are reduced and represent mostly the diurnal variability.

The year-to-year variability of coherence is shown in Figure 15. It shows the average correlations between plots that are in the same field compared to plots across fields. The correlations for plots within the fields are somewhat higher every year than the correiations of plots across fields, but these differences are relatively small and not statistically significant. When we consider the field average fluxes, the correlations between fields are much higher than the average correlations from the plot level calculations. These are also shown in Figure 15.

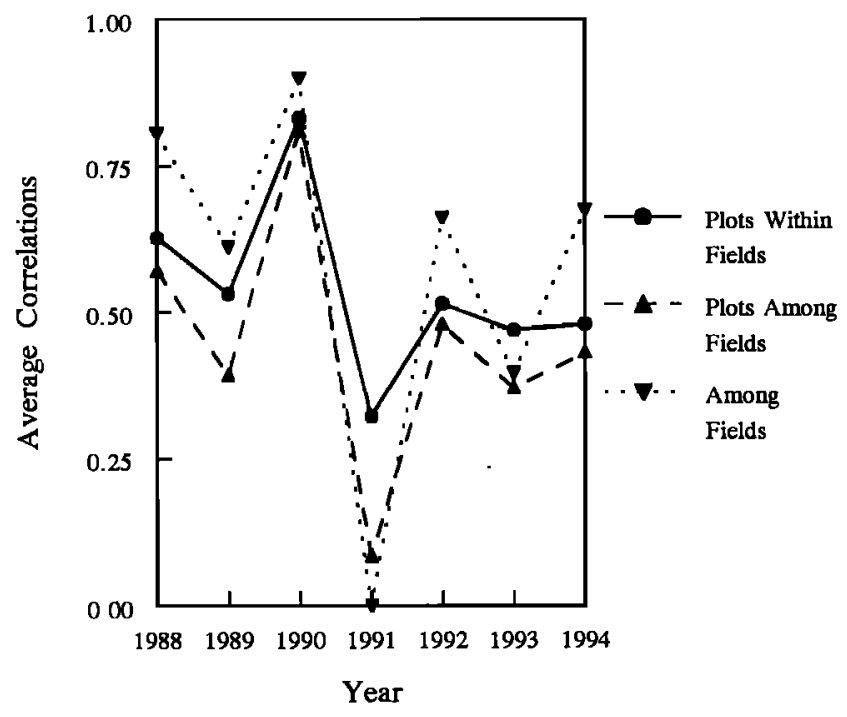

Figure 15. Average correlations of methane fluxes from different plots. "Plots within fields" refers to the average of correlations for plots compared to other plots in the same field; "plots among fields" refers to the comparisons of plots in one field, with plots in other fields; and Among Fields refers to the comparison of the average emissions recorded in each field to other fields. Explanations are given in the text.

There are two other noteworthy features. The correlations are very poor for the 1991 experiments. This, we believe, is due to the fewer measurements taken to represent each flux, the shorter times that the chambers were kept over the plants, and the sampling of fewer plots. Because of these results, we consider data for 1991 to be less reliable than for other years. Aside for this anomaly, there appears to be some slow degradation of the correlations over time.

Considering the seasonal averages of the absolute emission rates requires a different way of quantifying the variability. We chose the ratio of the maximum and minimum seasonal emissions. Two such ratios are

$$
\begin{aligned}
& \left.\rho_{1}(y)=\operatorname{Max}\{\Phi(p, f, y) \mid p, f\} / \operatorname{Min}\{\Phi(p, f, y) \mid p, f)\right\} \\
& \rho_{2}(y)=\operatorname{Max}\{\Phi(f, y) \mid f / \operatorname{Min}\{\Phi(f, y) \mid f)\}
\end{aligned}
$$

The first is the maximum to minimum ratio of fluxes from all plots $(p$ and $f$ ) over which measurements were taken in a given year $y$, regardless of which field these plots were in. And the second is the ratio of maximum to minimum fluxes obtained for each field in each year. The variability of the field averaged emissions is expected to be much less than the plot level calculations.

The results are shown in Figure 16 for $\rho_{1}(y)$ and $\rho_{2}(y)$. There are some noteworthy features. The maximum value of the ratio $\rho_{1}(y)$ is about 3 in 1990, which may in part be due to the loss of data during that year. As we showed earlier, missing data during the middle of the growing season can lead to an approximately $\pm 30 \%$ error in the plot level seasonal average flux calculation (a ratio of nearly 2). When the field averages are used to compare the variability each year, it is below 1.5, except in 1990 when it is 1.7. The variability of emissions among the fields is therefore quite small. 

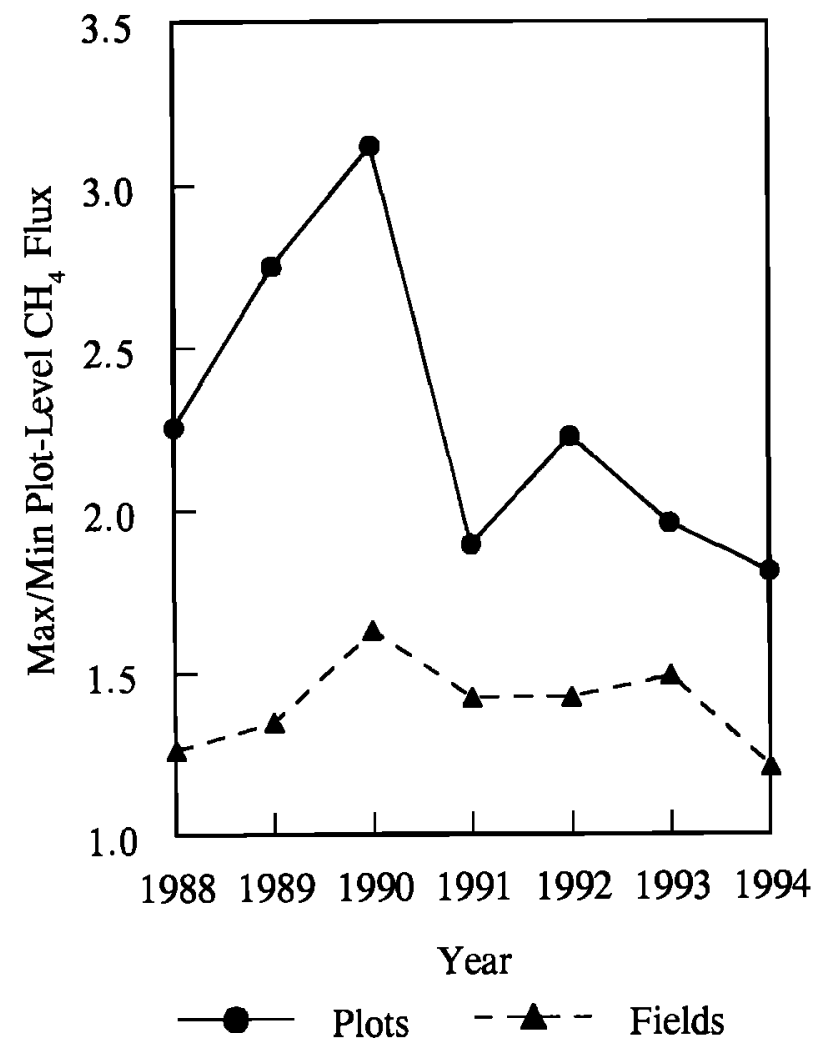

Figure 16. The ratio of maximum to minimum seasonally averaged emissions recorded at each "plot" during each year, and the same ratio for seasonally averaged and "field" averaged emissions.

As mentioned earlier, we expect the variability to be larger as we go to smaller and smaller spatial scales. This is in part because the emissions from the rice fields are determined mostly by the presence of plants and localized soil conditions, making it spatially quite heterogeneous. If a large area is sampled, this small scale variability is reduced as can be seen from the observations using the large chambers. The field average emission rate is equivalent to the use of larger chambers, since it is collectively a measure of the flux over the total area covered by the many chambers. For the large-scale extrapolation of the data, the plot to plot variability is not relevant, but rather what is applicable is the composite average of as many plots as were sampled. The variability of this area-wide average flux is much smaller as is shown in Figure 11 by the standard errors of the mean for each year. We conclude that sampling at a few small plots can lead to substantial errors in estimating the flux of methane from rice fields, but a composite of many small plots or large chambers is likely to represent the emissions from the rice field as a whole and can be extrapolated to larger regions. For this reason we believe that our data are best represented by "field" or "area" level averages.

5.3.2. Interannual variability. In the previous section we have discussed some aspects of the interannual variability, particularly as it relates to the reliability of the data. The remaining interannual variability is for the area-wide average fluxes, which is small. Two years, 1989 and 1990, show the most variability, being $-29 \%$ and $+33 \%$ from the mean emission rates for all years. The other years are much closer to the average emission rate over the 7 years (see Figure 13c). The data for the two anomalous years have been carefully examined, but no apparent cause for these fluctuations was found. No systematic trends were found in the area averaged data. The trends were 0.5 $\pm 1.2 \mathrm{mg} / \mathrm{m}^{2} / \mathrm{h}$ for all years and $0.3 \pm 0.9 \mathrm{mg} / \mathrm{m}^{2} / \mathrm{h}$ without 1989 1990 , where the \pm are standard errors of the trends.

We also considered the possibility whether one field may have systematically produced more or less methane than the other fields. We found no statistically significant differences in the average production rates of the fields over the seven years of study. The largest differences are between field 1 and field 4, which are also farthest apart from each other. For the 7-year period the average emissions from field 1 were $29 \mathrm{mg} / \mathrm{m}^{2} / \mathrm{h}$ during the growing seasons, and from field 4 the average emissions were $34 \mathrm{mg} / \mathrm{m}^{2} / \mathrm{h}$. The difference is about $5 \pm 8$ $\mathrm{mg} / \mathrm{m}^{2} / \mathrm{h}$.

5.3.3. Diurnal variations. Most previous studies have shown that there is a diurnal variation of methane emissions. The magnitude of the diumal cycle is different in different studies. In our case, the diumal variations are not large and are compatible with several studies reported earlier [Schütz et al., 1990b; Sass et al., 1991b; Cicerone et al., 1992]. It is probable that the diurnal variations of emissions are driven by the cycle of soil temperature near the surface [Schütz et al., 1989; Husin et al., 1995], but other factors are also likely to affect or even control the cycle [Khalil et al., this issue, b].

The emission of methane is lower at dawn and probably reaches a peak in late afternoon based on the results from 1993 and 1994, when we had measurements at four different times of the day (although not all on the same day). For the other years we have measurements at only two times of the day, early morning and afternoon. Either two measurements over the day or four give about the same results for the amplitude of the diumal cycle.

Our measure of the diurnal cycle is defined as follows: $\%$ Amplitude $=[$ Flux (evening) - Flux (morning) $] /$ AvgFlux (evening and morning) $\times 100 \%$. It is the difference of the evening and morning fluxes divided by the diurnally averaged flux. The average values were calculated by first taking the average of the difference and dividing it by the average flux, rather than calculating the \%Amplitude for each diurnal cycle and taking the average. The averaging procedure we selected safeguards against biases that can be introduced by the occasional large values of the \%Amplitude when the average flux is small.

Taking the composite data from all years, we calculated the percent diurnal variability during 15-day (non-over-lapping) periods of time since the rice was transplanted to harvest time. The calculated amplitude of the cycle is plotted in the middle of each 15-day period. The results are shown in Figure 17. In the early stages of growth the diurnal variability is quite large, reaching about $60 \%$ on average. The relative cycle amplitude falls during the growing season and is between $10 \%$ and $20 \%$ after the first 30 days since transplanting. This decreasing diurnal cycle amplitude has been observed before and explained by the effect of the rice plants on shading and moderating the diumal amplitude of soil temperature [Schütz et al., 1989]. Since the average fluxes are small during the early phase of growth, the percent change between day and night appears large, even though the absolute change is not.

The average amplitude of diurnal variation is between $10 \%$ and $20 \%$ for the whole growing season each year as shown in Figure 18. This amounts to a seasonally averaged cycle of between 3 and $6 \mathrm{mg} / \mathrm{m}^{2} / \mathrm{h}$. In 1991 no diumal variability was observed, but we believe this is due to the lower quality of the data in that year as explained earlier. In a companion paper, we will discuss the use of the simultaneous diumal variability of soil 


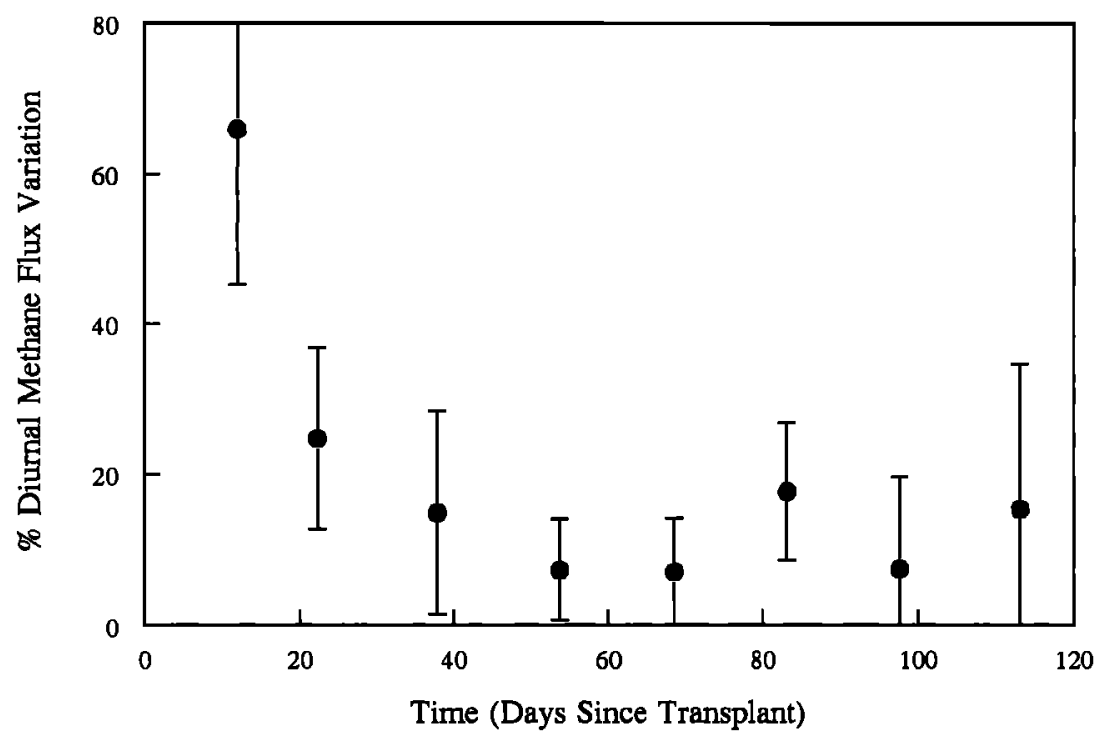

Figure 17. The diumal variability of methane emissions from rice fields during the course of the growing season. Results are a composite of all years of measurement with standard errors.

temperature and methane emissions as a measure of the effect of temperature on methane emissions [Khalil et al., this issue, b].

Because the experiments were done manually, the number of samples that could be collected during a day was limited. We obtained a composite of all years of data to look at the distribution of the samples during the day. To make the data from different years comparable, we subtracted the cycles of lengths longer than a day, leaving only the diurnal variations for the periods of our observations. Data from each plot were used for this calculation, and average emissions, from all years of data, were calculated for each hour of the day. The results showed that we had large amounts of data for 15 of the 24 hours of the day with 60 - 700 data points in each hour, and 30-400 data points in each hour when split over the different periods of the growth cycle (Figure 19). The biggest gap was between 1100 and 1700 hours. We had expected the peak emission to be around 1800 , and many data were obtained at that time. But it is possible that a peak occurred within the time when we did not take measurements (early afternoon), although the trends observed in Figure 19 do not favor this possibility. We tested the effect of this possibility on the seasonally averaged emission rates by assuming the peak occurred at about 1400 . We took the peak to be 5 to $10 \mathrm{mg} / \mathrm{m}^{2} / \mathrm{h}$ above the average value and linearly interpolated to the actual data at 1100 and 1700 . The effect of such peaks would be 0.5 to $1.2 \mathrm{mg} / \mathrm{m}^{2} / \mathrm{h}$ increase of the seasonally averaged flux (which is about $30 \mathrm{mg} / \mathrm{m}^{2} / \mathrm{h}$ ), or an error of less than $5 \%$.

\section{Comparisons With Similar Studies}

There have been many studies of methane emissions from rice fields, but only a few have reported results from fields under normal agricultural management. Even fewer studies have been conducted under the agricultural and environmental conditions

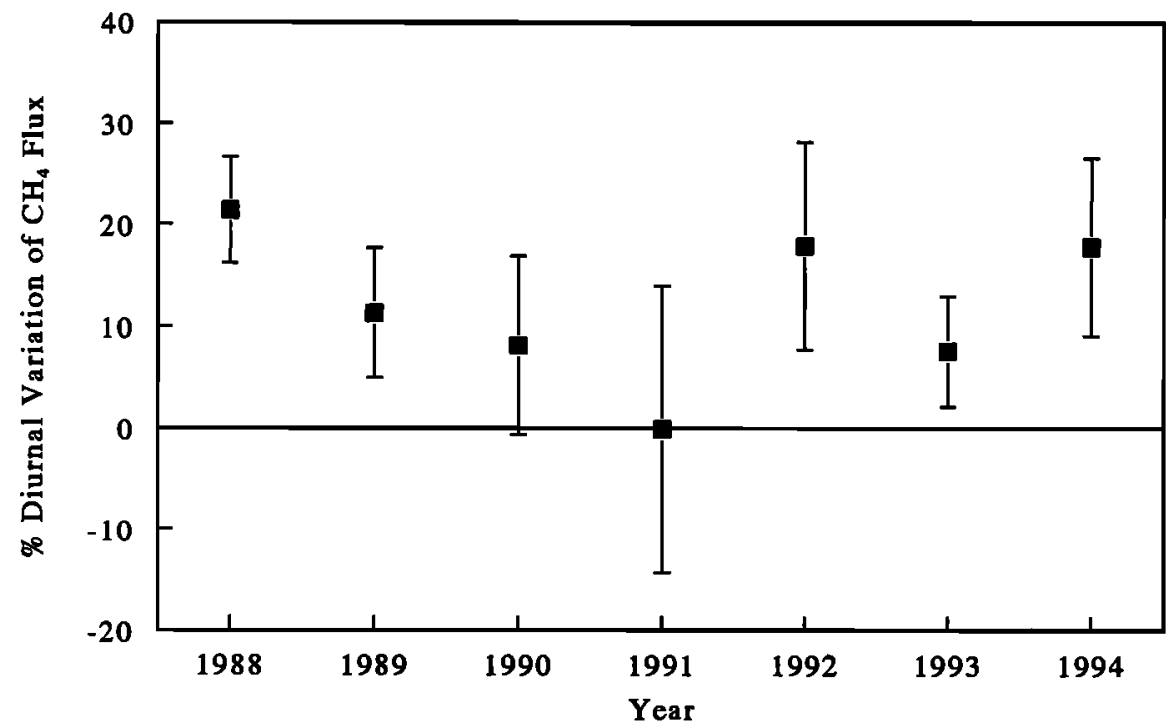

Figure 18. The average diumal cycle of methane emissions from rice fields in $\mathrm{Tu} \mathrm{Zu}$, China, for each year of the experiment (with standard errors). 


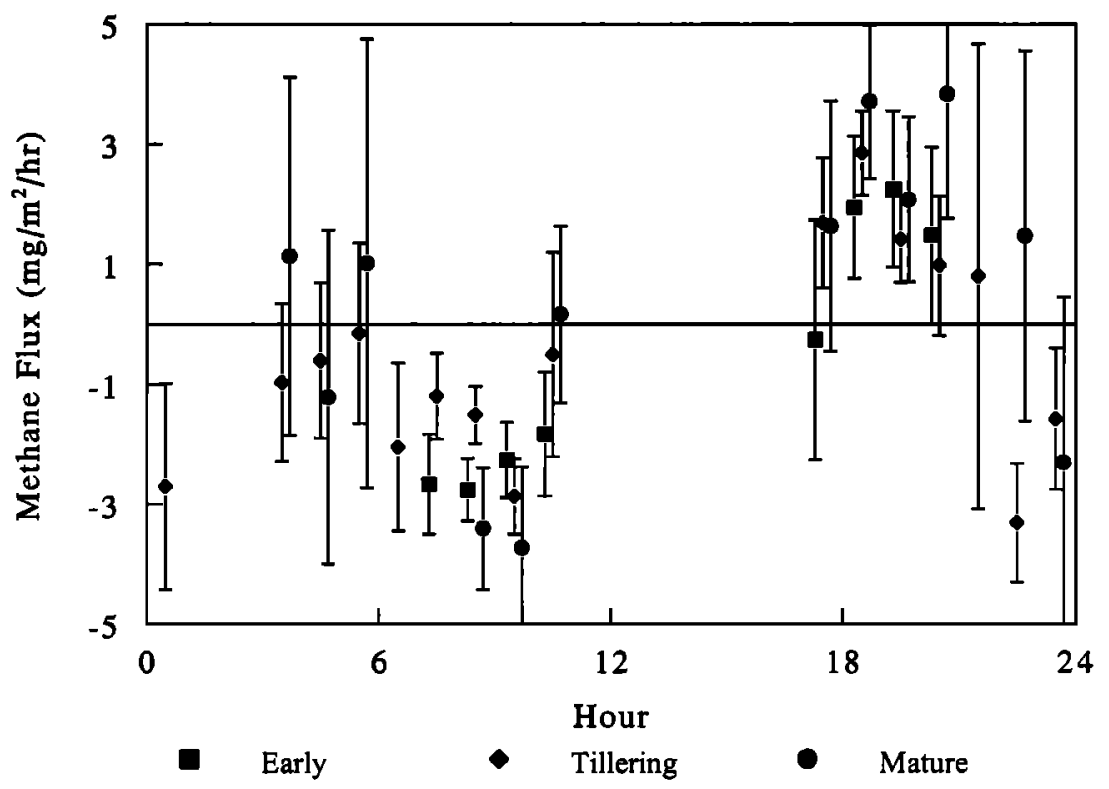

Figure 19. The average diurnal cycle of methane emissions from rice fields in $\mathrm{Tu} \mathrm{Zu}$, China, with standard errors (zero is midnight). The results represent a composite of data obtained between 1988 and 1994. All cycles longer than the diurnal cycle were subtracted from the data for each year to make data sets from different years comparable to each other.

similar to those for our study (an exception is the work of Sass et al. [1990, 1991a, b, 1992, 1994]). We developed a criterion for the similarity of other studies to our work at $\mathrm{Tu} \mathrm{Zu}$. Similarity was based on five factors namely, flooded irrigation, one midseason crop per year, use of organic fertilizer and inorganic nitrogen soil amendments, sandy loam soil, and soil organic matter more than $1 \%$. Results from such studies are shown in Table 5. These studies were done in China, Japan, India, Thailand, Indonesia, Philippines, Europe, and the United States. For studies that are similar to ours, on four or more out of the five criteria, the median whole season methane flux from China, other than from our study, is about $20 \mathrm{mg} / \mathrm{m}^{2} / \mathrm{h}$ with a range of $11-36$ $\mathrm{mg} / \mathrm{m}^{2} / \mathrm{h}$. Our data fall within this range, but on the higher side. Fewer studies have been reported from the other locations, but these generally show lower emission rates. The median flux from the other locations than China, is about $13 \mathrm{mg} / \mathrm{m}^{2} / \mathrm{h}$ with a range of $<1$ to $20 \mathrm{mg} / \mathrm{m}^{2} / \mathrm{hr}$. These results suggest that methane emissions from rice fields in China are likely to be higher than at other locations. While this was not expected, there are a number of explanations.

Studies have shown that the two most important factors affecting methane emissions are the application of organic fertilizer and water management. The relationship between organic fertilizer and methane emissions is complex and nonlinear. Generally, it seems that fields with little or no organic fertilizer applications will in time produce much less methane than comparable fields that have large organic fertilizer applications year after year. Some of the differences between the data from China compared to the other locations, particularly Japan, the United States, and Europe, is likely due to the longterm differences in the type and amount of organic fertilizers applied [Schütz et al., 1989; Yagi and Minami, 1990; Sass et al., 1991 a; Cicerone et al., 1992; Chen et al., 1993; Denier van der Gon and Neue, 1995].

Water management is another critical factor affecting whole season methane emissions from rice fields. When the water is allowed to evaporate and the fields are reflooded one or more times during the growing season, methane emissions can be very small compared to continuously flooded fields. At our research site, there was heavy use of organic fertilizer and the fields were continuously flooded as these are the prevailing farming practices in the area. In the other studies in China, the fields were also continuously flooded [Chen et al., 1993; Wassmann et al., 1993; Yao and Chen, 1994a, b], and variable amounts of organic fertilizer were used. This may explain some of the variability within the various experiments in China. The water management factor may also explain the low emissions reported from Indian rice fields as many of them are rain-fed [Debnath et al, 1996]. In some locations this may lead to intermittent flooding that has been shown to greatly reduce methane emissions in controlled experiments [Sass et al., 1992; Chen et al., 1993; Husin et al., 1995]. Moreover, the soil organic matter in Indian rice fields is likely to be much lower than other locations based on the few data that are available. This too would lead to lower emissions.

There are a number of other environmental factors and agricultural practices that can affect whole season methane emissions. Some of these were measured in our experiments and will be reported elsewhere [Khalil et al., this issue (b)]). The fraction of methane oxidized below the soil, soil temperature, rice cultivars, and soil characteristics all significantly affect methane emissions under prevailing agricultural practices [Schütz et al., 1990a; Sass et al., 1994; Neue et al., 1994; Husin et al., 1995]. The effect of these factors in explaining the differences between the various studies is not known at present. Nonetheless, it is likely that our results are higher than apparently similar studies because of a combination of several factors all conducive to higher emissions. These are inundated fields, large organic fertilizer applications, soil characteristics conducive to greater emissions [Neue et al., 1994], and possibly lower methane oxidation than usual [Khalil et al., this issue, (c)]. The differences of observed emissions due to any one of these factors is enough to explain the differences between our observations and those reported by others.

There are times when the management of the fields can either 
Table 5. Comparison of Methane Emissions at Tu Zu with Other Similar Studies.

\begin{tabular}{|c|c|c|c|c|c|c|}
\hline Study & Country & Latitude & Longitude & $\begin{array}{c}\text { Organic } \\
\text { Amendments, } \\
\text { tonnes/ha }\end{array}$ & $\begin{array}{c}\text { Mineral } \\
\text { Fertilizer, } \\
\text { kg N/ha }\end{array}$ & $\begin{array}{c}\text { Seasonal } \\
\text { Average } \\
\text { Flux, } \\
\mathrm{mg} / \mathrm{m}^{2} / \mathrm{h}\end{array}$ \\
\hline This study ${ }^{2}$ & China & $29.5^{\circ} \mathrm{N}$ & $106.7^{\circ} \mathrm{E}$ & $14-38$ & $50-100$ & 30 \\
\hline \multicolumn{7}{|c|}{ Studies Meeting All Criteria } \\
\hline $\begin{array}{l}\text { Chen et al. }[1993]^{\mathrm{b}} \\
\text { Schütz et al. }[1989]^{\mathrm{c}}\end{array}$ & $\begin{array}{l}\text { China } \\
\text { Italy }\end{array}$ & $\begin{array}{r}40^{\circ} \mathrm{N} \\
45^{\circ} 20^{\prime} \mathrm{N}\end{array}$ & $\begin{array}{r}116^{\circ} \mathrm{E} \\
8^{\circ} 25^{\prime} \mathrm{E}\end{array}$ & $\begin{array}{l}15-30 \\
2.5-12\end{array}$ & $\begin{array}{c}108 \\
38-200\end{array}$ & $\begin{array}{l}42 \\
19\end{array}$ \\
\hline \multicolumn{7}{|c|}{ Studies Meeting Four Out of Five Criteria } \\
\hline Yagi and Minami $[1990]^{\mathrm{d}}$ & Japan & $35^{\circ} 61^{\prime} \mathrm{N}$ & $140^{\circ} 13^{\prime} \mathrm{E}$ & 6 & 90 & 6 \\
\hline Wassmann et al. $[1993]^{\mathrm{e}}$ & China & $30^{\circ} 19^{\prime} \mathrm{N}$ & $120^{\circ} 12^{\prime} \mathrm{E}$ & 1 & 0 & 32 \\
\hline Wassmann et al. $[1993]^{\mathrm{f}}$ & China & $30^{\circ} 19^{\prime} \mathrm{N}$ & $120^{\circ} 12^{\prime} \mathrm{E}$ & 1 & 0 & 17 \\
\hline Chen et al. $[1993]^{\mathrm{B}}$ & China & $32^{\circ} \mathrm{N}$ & $118^{\circ} 40^{\prime} \mathrm{E}$ & 15 & 90 & 11 \\
\hline Husin et al. $[1995]^{\mathrm{h}}$ & Indonesia & $6^{\circ} 20^{\prime} \mathrm{S}$ & $107^{\circ} 39^{\circ} \mathrm{E}$ & 7 & 117 & 17 \\
\hline Sass et al. $[1990,1991 \mathrm{a}, 1991 \mathrm{~b}, 1994]^{\prime}$ & USA & $27^{\circ} 57^{\prime} \mathrm{N}$ & $94^{\circ} 30^{\prime} \mathrm{W}$ & $2-12$ & $100-200$ & 10 \\
\hline Lauren et al. $[1994]^{\jmath}$ & USA & $38^{\circ} \mathrm{N}$ & $122^{\circ} \mathrm{W}$ & 9 & 200 & 17 \\
\hline \multicolumn{7}{|c|}{ Studies Meeting Three Out of Five Criteria } \\
\hline Yao and Chen $[1994 \mathrm{~b}]^{\mathrm{k}}$ & China & $40^{\circ} 30^{\prime} \mathrm{N}$ & $116^{\circ} 25^{\prime} \mathrm{E}$ & 10 & 150 & 22 \\
\hline Yagi and Minami $[1990]^{\prime}$ & Japan & $36^{\circ} 1^{\prime} \mathrm{N}$ & $140^{\circ} 7^{\prime} \mathrm{E}$ & 6 & 100 & 0.3 \\
\hline Yagi and Minami $[1990]^{m}$ & Japan & $36^{\circ} \mathrm{N}$ & $140^{\circ} \mathrm{E}$ & 6 & 85 & 16 \\
\hline Yagi and Minami $[1990]^{n}$ & Japan & $36^{\circ} \mathrm{N}$ & $140^{\circ} \mathrm{E}$ & 6 & 80 & 3 \\
\hline Denier van der Gon and Neue $[1994,1995]^{\circ}$ & Philippines & $14^{\circ} 50^{\prime} \mathrm{N}$ & $121^{\circ} \mathrm{E}$ & 9 & 64 & 7 \\
\hline Denier van der Gon and Neue $[1994,1995]^{p}$ & Philippines & $14^{\circ} 50^{\prime} \mathrm{N}$ & $121^{\circ} \mathrm{E}$ & 11 & 103 & 20 \\
\hline Debnath et al. $[1996]^{9}$ & India & $28^{\circ} 40^{\prime} \mathrm{N}$ & $77^{\circ} \mathrm{E}$ & 8 & 60 & 2 \\
\hline \multicolumn{7}{|c|}{ Studies Meeting One or Two Out of Five Criteria } \\
\hline Lal et al. $[1993]^{r}$ & India & $10^{\circ} 50^{\prime} \mathrm{N}$ & $79^{\circ} 8^{\prime} \mathrm{E}$ & 5 & 34 & 8 \\
\hline Seiler et al. $[1984]^{\mathrm{s}}$ & Spain & $37^{\circ} 6^{\prime} \mathrm{N}$ & $5^{\circ} 28^{\prime} \mathrm{W}$ & 0 & 200 & 4 \\
\hline Cicerone et al. [1983 and 1992]' & USA & $38^{\circ} 30^{\prime} \mathrm{N}$ & $121^{\circ} 50^{\prime} \mathrm{W}$ & 0 & 114 & 7 \\
\hline Lindau et al. $[1991]^{u}$ & USA & $30^{\circ} 7 \mathrm{~N}$ & $92^{\circ} 15^{\prime} \mathrm{W}$ & 0 & 200 & 15 \\
\hline Adhya et al. $[1994]^{v}$ & India & $20^{\circ} 30^{\prime} \mathrm{N}$ & $86^{\circ} \mathrm{E}$ & 0 & 40 & $7-15$ \\
\hline Parashar et al. [1996]" & India & & & & & $0-26$ \\
\hline
\end{tabular}

Criteria for similarity are flooded irrigation, one midseason rice crop, organic and mineral soil amendments, sandy loam soil, and soil organic matter greater than $1 \%$.

a Soil amendments show the range of applications for all years; organic amendments were usually manure or biogas sludge; chemical fertilizers were usually urea or a compound (N P K) fertilizer.

b Average of two experiments with flooded irrigation, nitrogen fertilizers and large applications of manure, matching the management at Tu $\mathrm{Zu}$.

c Average of 1984 to 1986 growing seasons, treatments with both rice straw and nitrogenous fertilizers.

d Ryugasaki research site, flood irrigation with one mid-season drainage.

e-f Double season crop: Footnote $e$ is late season rice; footnote $f$ is early season rice; experiment with both mineral fertilizer $\left(\mathrm{K}_{2} \mathrm{SO}_{4}\right)$ and organic (rape seed cake or manure) treatments.

B- Studies that do not have the same soil type as $\mathrm{Tu} \mathrm{Zu}$, or soil type is not known.

g Fields are flood irrigated through tillering, intermittently irrigated through second half of growing season.

h Average of flux from two cultivars; clay soil.

' Average of three soil types with 24 - $65 \%$ clay. Experiments with incorporated straw and flooded irrigation only are averaged here.

' Loam soil.

k This is an average of the flooded irrigation, nitrogen fertilizer treatment, and intermittent irrigation with horse manure and nitrogen fertilizer treatments.

l-n Mid-season drainage. Footnote I: Tsukuba research site, light-colored Andosol loam soil; footnote m: Kawachi research site; Clay loam; peat soil; footnote n: Mito research site; humic Andosol, loam soil.

o,p Clay soil; two crop growing season: wet season (footnote o); dry season (footnote p).

${ }^{q}$ Kharif (wet) season; $0.4 \%$ soil organic matter.

${ }^{r}$ No soil information; growing season September to January; fluxes estimated from Figure 3 in reference.

s-u Low or unknown soil organic matter; footnote s: soil type not given; footnote t: clay soil; footnote u: silt loam soil.

v Clay loam soil; fluxes estimated from Table 3 in reference.

w Only the range of fluxes is shown from 16 sites, under various management, most measured for less than a season 
increase or decrease daily emission rates. If the fields are drained during the growing season, to apply fertilizer for instance, emissions may be lowered for some time. These events are captured by our sampling protocol. But occasionally, there are other intrusions by farmers, as during puddling, transplanting, and harrowing, when trapped methane can be released. Based on qualitative data and observations, we believe that such releases occur for very short periods of time and therefore do not significantly affect the seasonal emission rates calculated here.

\section{Conclusions}

In this paper we have described a 7-year experiment to determine the emission rate of methane from rice fields in China and the factors that control these emissions. The paper deals with the data acquired in this experiment, laying the foundation for further interpretation of these data in subsequent papers, and for readers to use the data in their own research.

The results show that methane emissions vary systematically during the growing season and during the day. Emissions also vary from year to year. Emissions are small in the beginning of the growing season and reach a peak rate around flowering time; after then, emissions start to fall. Some of the within-season changes in emission rates are explained by changes in soil temperature during the season. The diumal variability is relatively small and may be due to soil temperature variations.

None of the four fields we studied emitted systematically more or less methane than any other field during the seven years of the experiment. This result suggests that large-scale extrapolations based on the data are likely to be robust. Small-scale variability, on the other hand, is very large. To overcome the effects of small-scale variability, either many spatial replicates have to be done or large chambers have to be used, so that a substantial part of the rice field is sampled.

These data show interannual variability but no trends in the emissions over the 7-year period. There are 2 years, 1989 and 1990 , that have the lowest $\left(22 \mathrm{mg} / \mathrm{m}^{2} / \mathrm{h}\right)$ and highest $(40$ $\mathrm{mg} / \mathrm{m}^{2} / \mathrm{h}$ ) seasonal emission rates during the course of the experiment. Some of this effect is likely to be caused by the experimental process, including the fact that the instrument failed for part of the growing season in 1990 . There is only $+15 \%$ to $25 \%$ difference from year to year for the other 6 years of the experiment. We believe that the measured interannual variability is small given the complexities of the processes involved. The whole season methane emissions calculated from this experiment are around $30 \mathrm{mg} / \mathrm{m}^{2} / \mathrm{h}$, which are consistent with other comparable studies in China.

In spite of many years of research on methane emissions from rice fields, there are relatively few studies that have investigated the emission rates for the whole growing season under prevailing agricultural practices. The results that have emerged show some remarkable consistencies but also substantial spatial and regional variability, the causes of which are not clearly understood. For continuously flooded rice fields, with use of organic fertilizers, the emission rates are $20-40 \mathrm{mg} / \mathrm{m}^{2} / \mathrm{h}$, which includes our study. With intermittent flooding and use of mineral fertilizers alone, the emission rates can be substantially smaller. The results of all these studies suggest that the global emissions of methane from rice fields are substantially smaller than originally thought and are likely to be in the range of $40-80 \mathrm{Tg} / \mathrm{yr}$. This range includes estimates of emissions from fallow fields, on which there are very few available data at present. The range may be narrowed by a more complete analysis of how the data should be extrapolated to the global scale, but the uncertainty is unlikely to improve much without the use of new experimental technology and theoretical advances.

Acknowledgments. This project was supported by the U.S. Department of Energy (DE-FG06-85ER60313). We thank Michael Riches for his many suggestions and his help with the logistics of carrying out the experiments. We thank Wang Ming-Xing (IAP), Francis Moraes (PSU), and Donald Stearns (OGI) for their contr ibutions to this project. Additional support was provided by the Biospherics Corporation and the Andarz Co.

\section{References}

Adhya, T. K., A. K. Rath, P. K. Gupta, V. R. Rao, S. N. Das, K. M. Parida, D. C. Parashar, and N. Sethunathan, Methane emission from flooded rice fields under irrigated conditions, Biol. Fert. Soils, 18, 245-248, 1994.

Chen, Z., L. Debo, K. Shao, and B. Wang, Features of $\mathrm{CH}_{4}$ emission from rice paddy fields in Beijing and Nanjing, China, Chemosphere, 26(1-4), 239-246, 1993.

Cicerone, R. J., J. D. Shetter, and C. C. Delwiche, Seasonal variation of methane flux from a California rice paddy, J. Geophys. Res., $88(\mathrm{Cl} 15)$, 11,022-11,024, 1983.

Cicerone, R. J., C. C. Delwiche, S. C. Tyler, and P. R. Zimmerman, Methane emissions from California rice paddies with varied treatments, Global Biogeochem. Cycles, 6(3), 233-248, 1992.

Debnath, G., M. C. Jain, S. Kumar, K. Sarker, and S. K. Sinha, Methane emissions from rice fields amended with biogas slurry and farm yard manure, Clim. Change, 6, 97-109, 1996.

Denier van der Gon, H. C., and H. U. Neue, Impact of gypsum application on the methane emission from a wetland rice field, Global Biogeochem. Cycles, 8(2), 127-134, 1994.

Denier van der Gon, H. C., and H. U. Neue, Influence of organic matter incorporation on the methane emission from a wetland rice field, Global Biogeochem. Cycles, 9(1), 11-22, 1995.

Grıst, D. H, Rice, $6^{\text {th }}$ Edition, Tropical Agriculture Series, Longman Group, Inc., New York 1986.

Husin, Y. A., D. Murdiyarso, M. A. K. Khahl, R. A. Rasmussen, M. J. Shearer, S. Sabiham, A. Sunar, and H. Adijuwana, Methane flux from Indonesian wetland rice: The effects of water management and rice variety, Chemosphere, 31(4), 3153-3180, 1995.

Khalil, M. A. K., and R. A. Rasmussen, Constraints on the global sources of methane and an analysis of recent budgets. Tellus, 42B, 229-236, 1990.

Khalil, M. A. K., and R. A. Rasmussen, Using ambient concentrations as proxy for methane flux measurements from rice fields, in press, Chemosphere, 1998.

Khalil, M. A., K., R. A. Rasmussen, M.- X. Wang, and L. X. Ren, Emissions of trace gases from Chinese rice fields and biogas generators: $\mathrm{CH}_{4}, \mathrm{~N}_{2} \mathrm{O}, \mathrm{CO}, \mathrm{CO}_{2}$, chlorocarbons, and hydrocarbons, Chemosphere, 20(1-2), 207-226, 1990.

Khalil, M. A. K., R. A. Rasmussen, M.-X. Wang, and L. X. Ren, Methane emissions from rice fields in China, Environ. Sci. Technol., 25, 979-981, 1991.

Khalil, M. A. K., R. A. Rasmussen, and M. J. Shearer, Flux measurements and sampling strategies: Applications to methane emissions from rice fields, this issue, 1998a.

Khalil, M. A. K., R. A. Rasmussen, M. J. Shearer, R. W. Dalluge, L. X. Ren, and C.- L. Duan, Factors affecting methane emissions from rice fields, this issue, $1998 \mathrm{~b}$.

Khalil, M. A. K., R. A. Rasmussen, and M. J. Shearer, The effect of planting density, oxidation, and root exudates on methane emissions from rice fields, this issue, 1998c.

Lal, S., S. Venkataramani, and B. H. Subbaraya, Methane flux measurements from paddy fields in the tropical Indian region, Atmos. Environ., 27A(11), 1691-1694, 1993.

Lauren, J. G., G. S. Pettygrove, and J. M. Duxbury, Methane emissions associated with a green manure amendment to flooded rice in Califomia. Biogeochemistry, 24, 53-65, 1994.

Lindau, C. W., P. K. Bollich, R. D. DeLaune, W. H. Patrick, Jr., and V. J. Law, Effect of urea fertilizer and environmental factors on $\mathrm{CH}_{4}$ 
emissions from a Louisiana, USA rice field, Plant Soil, 136, 195-203, 1991.

Neue, H.- U., R. S. Lantin, R. Wassmann, J. B. Aduna, M. C. R. Alberto, and $M$. J. F. Andales, Methane emission from rice soils of the Philippines, in $\mathrm{CH}_{4}$ and $\mathrm{N}_{2} \mathrm{O}$ : Global Emissions and Controls From Rice Fields and Other Agricultural and Industrial Sources, edited by K. Minami, A. Mosier, and R. Sass, pp. 55-63, NIAES, Yokendo, Tokyo, Japan, 1994.

Parashar, D. C., et al., Methane budget from paddy fields in India, Chemosphere 33(4), 737-757, 1996.

Rasmussen, R. A., and M. A. K. Khalil, Increase in the concentration of atmospheric methane, Atmos. Environ. 15(5), 883-886, 1981.

Riches, M. R., J. Zhao, W.- C. Wang, S. Tao, The U.S. Department of Energy and the People's Republic of China's Academy of Sciences joint research on the greenhouse effect: 1985-1991 research progress, Bull. Am. Meterol. Soc., 73(5) (5), 585-594, 1992.

Sass, R. L., F. M. Fisher, P. A. Harcombe, and F. T. Tumer, Methane production and emission in a Texas rice field, Global Biogeochem. Cycles, 4(1), 47-68, 1990.

Sass, R. L., F. M. Fisher, P. A. Harcombe, and F. T. Turner, Mitigation of methane emissions from rice fields: Possible adverse effects of incorporated rice straw, Global Biogeochem. Cycles, 5(3), 275-287, 1991 a.

Sass, R .L., F. M. Fisher, F. T. Turner, and M. F. Jund, Methane emission from rice fields as influenced by solar radiation, temperature, and straw incorporation, Global Biogeochem. Cycles, 5(4), 335-350, $1991 \mathrm{~b}$.

Sass, R. L., F. M. Fisher, Y. B. Wang, F. T. Tumer, and M. F. Jund, Methane emission from rice fields: The effect of floodwater management, Global Biogeochem. Cycles, 6(3), 249-262, 1992.

Sass, R. L., F. M. Fisher, S. T. Lewis, M. F. Jund, and F. T. Tumer, Methane emissions from rice fields: Effect of soil properties, Global Biogeochem. Cycles, 8(2), 135-140, 1994.

Schütz, H., A. Holzapfel-Pschom, R. Conrad, H. Rennenberg, and W. Seiler, A 3-year continuous record on the influence of daytime, season, and fertilizer treatment on methane emission rates from an Italian rice paddy, J. Geophys. Res., 94(D13), 16,405-16,416, 1989.

Schütz, H., W. Seiler, and R. Conrad, Influence of soil temperature on methane emission from rice paddy fields, Biogeochemistry, 11, 77-95, 1990a.
Schütz, H., W. Seiler, and H. Rennenberg, Soil and land use related sources and sinks of methane $\left(\mathrm{CH}_{4}\right)$ in the context of the global methane budget, in Soils and the Greenhouse Effect, edited by A.F. Bouwman, John Wiley, New York, 1990b.

Seiler, W., A. Holzapfel-Pschorn, R. Conrad, and D. Scharffe, Methane emission from rice paddies, J. Atmos. Chem., 1, 241-268, 1984.

USSR Academy of Sciences, Institute of Geography, he Physical Geography of China, vol. 1., F. A. Praeger, New York, 1969.

Wassmann, R., H. Schütz, H. Papen, H. Rennenberg, W. Seiler, A. G. Dai, R. X. Shen, X. J. Shangguan, and M. W. Wang, Quantification of methane emissions from Chinese rice fields (Zhejiang Province) as influenced by fertilizer treatment, Biogeochemistry 20, 83-101, 1993.

Xu Guohua, Natural environment, in The Agriculture of China, edited by Xu Guohua and L. J. Peel, pp. 1-41, Oxford Univ. Press, New York, 1991.

Yagi, K., and K. Minami, Effect of organic matter application on methane emission from some Japanese paddy fields, Soil Sci. Plant Nutrition, 36(4), 599-610, 1990.

Yao, H., and Z. L. Chen, Effect of chemical fertilizer on methane emission from rice paddies, J. Geophys. Res., 99(D8), 16,463$16,470,1994 a$.

Yao H., and Z. L. Chen, Seasonal variation of methane flux from a Chinese rice paddy in a semi arid, temperate region, J. Geophys. Res. 99(D8), 16,471-16,477, 1994b.

Zhao, S. The Physical Geography of China, Wiley-Interscience, New York, 1986.

R. W. Dalluge and R. A. Rasmussen, Department of Environmental Science and Engineering, Oregon Graduate Institute, P.O. Box 91000, Portland, OR 97291.

C.- L. Duan, Institute of Mountain Disasters and the Environment, P.O. Box 417, Chengdu, Sichuan 610041, China.

M. A. K. Khalil and M. J. Shearer, Department of Physics, Portland State University, P.O. Box 751, Portland, OR 97207-0751.

L.-X. Ren, Institute of Atmospheric Physics, Academia Sinica, Beijing 100029, China.

(Received January 21, 1997; revised September 10, 1997; accepted September 11, 1997.) 